\title{
Differential Regulation of Action Potential Shape and Burst- Frequency Firing by BK and Kv2 Channels in Substantia Nigra Dopaminergic Neurons
}

\author{
Tilia Kimm, ${ }^{1}$ Zayd M. Khaliq, ${ }^{2}$ and Bruce P. Bean ${ }^{1}$ \\ ${ }^{1}$ Department of Neurobiology, Harvard Medical School, Boston, Massachusetts 02115, and ${ }^{2}$ Cellular Neurophysiology Unit, National Institute of \\ Neurological Disorders and Stroke, National Institutes of Health, Bethesda, Maryland 20892
}

Little is known about the voltage-dependent potassium currents underlying spike repolarization in midbrain dopaminergic neurons. Studying mouse substantia nigra pars compacta dopaminergic neurons both in brain slice and after acute dissociation, we found that BK calcium-activated potassium channels and Kv2 channels both make major contributions to the depolarization-activated potassium current. Inhibiting Kv2 or BK channels had very different effects on spike shape and evoked firing. Inhibiting Kv2 channels increased spike width and decreased the afterhyperpolarization, as expected for loss of an action potential-activated potassium conductance. BK inhibition also increased spike width but paradoxically increased the afterhyperpolarization. Kv2 channel inhibition steeply increased the slope of the frequency-current $(f-I)$ relationship, whereas BK channel inhibition had little effect on the $f-I$ slope or decreased it, sometimes resulting in slowed firing. Action potential clamp experiments showed that both BK and Kv2 current flow during spike repolarization but with very different kinetics, with Kv2 current activating later and deactivating more slowly. Further experiments revealed that inhibiting either BK or Kv2 alone leads to recruitment of additional current through the other channel type during the action potential as a consequence of changes in spike shape. Enhancement of slowly deactivating Kv2 current can account for the increased afterhyperpolarization produced by BK inhibition and likely underlies the very different effects on the $f-I$ relationship. The crossregulation of $\mathrm{BK}$ and $\mathrm{Kv} 2$ activation illustrates that the functional role of a channel cannot be defined in isolation but depends critically on the context of the other conductances in the cell.

Key words: action potential clamp; bursting; guangxitoxin-1E; paxilline

\section{Significance Statement}

This work shows that BK calcium-activated potassium channels and Kv2 voltage-activated potassium channels both regulate action potentials in dopamine neurons of the substantia nigra pars compacta. Although both channel types participate in action potential repolarization about equally, they have contrasting and partially opposite effects in regulating neuronal firing at frequencies typical of bursting. Our analysis shows that this results from their different kinetic properties, with fast-activating BK channels serving to short-circuit activation of Kv2 channels, which tend to slow firing by producing a deep afterhyperpolarization. The cross-regulation of BK and Kv2 activation illustrates that the functional role of a channel cannot be defined in isolation but depends critically on the context of the other conductances in the cell.

\section{Introduction}

Electrical activity in the nervous system is finely tuned by the diverse populations of ion channels expressed by different types

Received Dec. 30, 2014; revised 0ct. 9, 2015; accepted Nov. 11, 2015.

Author contributions: T.K., Z.M.K., and B.P.B. designed research; T.K. and Z.M.K. performed research; T.K., Z.M.K., and B.P.B. analyzed data; T.K., Z.M.K., and B.P.B. wrote the paper.

This work was supported by NINDS R01NS036855, F31NS080323, and the NINDS Intramural Program. We thank to Dr Michelino Puopolo (Stony Brook University) for sharing preliminary results, and for help and advice, and to Dr Rachel Wilson for helpful discussion.

The authors declare no competing financial interests.

Correspondence should be addressed to Bruce P. Bean, Harvard Medical School, 220 Longwood Avenue, Boston, MA 02115.E-mail: bruce_bean@hms.harvard.edu. of neurons (Llinás, 1988; Hille, 2001). In general, the relationship between the ion channels found in a cell and the cell's electrical input-output properties is complex and impossible to predict a priori. In some circumstances, very different sets of ion channel populations can produce similar outputs; in others, small modulations in even one conductance can lead to dramatic changes in overall excitability (Goldman et al., 2001; Swensen and Bean, 2005; Amendola et al., 2012). In mammalian central neurons, 
there is a particularly large number and diversity of voltageactivated and calcium-activated potassium channels (Vacher et al., 2008), which help confer different firing properties on different types of neurons (Johnston et al., 2010).

Dopaminergic neurons of the substantia nigra pars compacta (SNc) exhibit two different modes of activity: slow spontaneous pacemaking and higher-frequency burst firing evoked by glutamatergic input (Grace and Bunney, 1984a,b). Substantial work has explored the calcium and sodium currents driving pacemaking (Chan et al., 2007; Puopolo et al., 2007; Guzman et al., 2009; Putzier et al., 2009; Ding et al., 2011; Tucker et al., 2012) and has elucidated mechanisms by which pacemaking can be controlled by Kv4-mediated A-type current and SK calcium-activated potassium current flowing between spikes (Liss et al., 2001; Wolfart et al., 2001; Hahn et el., 2003; Khaliq and Bean, 2008; Herrik et al., 2010; Deignan et al., 2012). In contrast, very little is known about the voltage-dependent potassium currents that underlie spike repolarization.

Control of burst firing is especially complex and is known to involve many different channel types (for review, see Paladini and Roeper, 2014). A number of channels have been shown to regulate the transition between tonic firing and bursting, including NMDA receptors (Deister et al., 2009; Paladini and Roeper, 2014), SK calcium-activated channels (Shepard and Bunney, 1991; Wolfart and Roeper, 2002; Waroux et al., 2005), Kv7mediated M-current (Drion et al., 2010), and K-ATP channels (Schiemann et al., 2012). However, all of these potassium currents are slowly gating, and none are likely to be the dominant potassium currents controlling rapid repolarization of spikes within bursts. In addition to helping control frequency of firing within bursts, such potassium currents are likely to help control entry into the state of depolarization block, to which dopamine neurons appear particularly susceptible (Grace and Bunney, 1986; Grace et al., 1997; Blythe et al., 2009; Tucker et al., 2012; Qian et al., 2014).

We investigated depolarization-activated potassium currents in SNc dopamine neurons. Using selective blockers, we found that BK channels and Kv2 channels each carry a large fraction of the potassium current underlying spike repolarization, but with very different kinetics. Inhibiting BK channels produced dramatic spike broadening accompanied by a paradoxically more negative afterhyperpolarization. We found that this could be explained by enhancement of Kv2 current during spikes broadened by BK inhibition. There is a reciprocal recruitment of BK current following Kv2 inhibition. These effects likely contribute to very different effects on burst-frequency firing, with Kv2 inhibition but not BK inhibition producing a steeper dependence on stimulating current.

\section{Materials and Methods}

Slice preparation and identification of cells. Coronal brain slices containing the substantia nigra pars compacta were prepared from postnatal day (P)14-P21 Swiss Webster mice of either sex. Animals were anesthetized with isoflurane and decapitated. Their brains were quickly removed and placed into an ice-cold sucrose slicing solution containing the following (in mM): 250 glycerol, $2.5 \mathrm{KCl}, 2 \mathrm{MgCl}_{2}, 2 \mathrm{CaCl}_{2}, 1.2 \mathrm{NaH}_{2} \mathrm{PO}_{4}, 10$ HEPES, $21 \mathrm{NaHCO}_{3}$, and 5 glucose, bubbled with $95 / 5 \% \mathrm{O}_{2} / \mathrm{CO}_{2}$. Slices were cut ( $300 \mu \mathrm{m}$ thick) and incubated for $30 \mathrm{~min}$ at $34^{\circ} \mathrm{C}$ in artificial CSF (ASCF) consisting of the following (in mM): $125 \mathrm{NaCl}, 25 \mathrm{NaHCO}_{3}, 1.25$ $\mathrm{NaH}_{2} \mathrm{PO}_{4}, 3.5 \mathrm{KCl}, 1 \mathrm{MgCl}_{2}, 2 \mathrm{CaCl}_{2}$, and 10 glucose, bubbled with $95 / 5 \% \mathrm{O}_{2} / \mathrm{CO}_{2}$. Slices were stored at room temperature until use.

Slice electrophysiological recording. Slices were placed into a heated recording chamber $\left(34 \pm 1^{\circ} \mathrm{C}\right)$ and continuously perfused with ACSF at a rate of $3 \mathrm{ml} / \mathrm{min}$ until the recording began. Neurons in the SNc were visualized using a CCD camera (Hamamatsu) on an Olympus microscope (BX51). Dopamine neurons were identified based on location in the $\mathrm{SNc}$, large size, slow pacemaker firing, broad action potentials, and a large depolarizing sag in response to hyperpolarizing current injection. In voltage-clamp experiments, cells were identified based on cell size, a large $I_{\mathrm{h}}$ evoked by hyperpolarizing pulses, and a large amplitude A-type potassium current, known to be prominent in these cells (Liss et al., 2001; Hahn et al., 2003). Whole-cell current-clamp or voltage-clamp recordings were made with a Multiclamp 700B amplifier (Molecular Devices) using borosilicate patch electrodes (1-4 M $\Omega$ ) wrapped with Parafilm to reduce pipette capacitance. Pipette series resistance (typically 4-8 M $\Omega$ ) was compensated by $70-85 \%$ during voltage-clamp experiments and was checked frequently throughout the experiment; data were not used if series resistance changed by $>20 \%$. Current and voltage signals were filtered at $10 \mathrm{kHz}$ and sampled at $20 \mu$ s using a Digidata $1440 \mathrm{~A}$ dataacquisition interface (Molecular Devices) and pClamp 10 software (Molecular Devices).

Slice recording solutions. The internal solution consisted of $122 \mathrm{~mm} \mathrm{~K}$ methanesulfonate, $9 \mathrm{~mm} \mathrm{NaCl}, 1.8 \mathrm{~mm} \mathrm{MgCl}_{2}, 4 \mathrm{~mm} \mathrm{Mg-ATP,} 0.3 \mathrm{~mm}$ Na-GTP, 14 mm phosphocreatine, 0.45 EGTA, $0.1 \mathrm{CaCl}_{2}$, and $10 \mathrm{HEPES}$, $\mathrm{pH}$ adjusted to $\mathrm{pH} 7.35$ with $\sim 18 \mathrm{~mm} \mathrm{KOH}$. Reported voltages are corrected for a liquid junction potential of $-8 \mathrm{mV}$ between the internal solution and the external solution in which pipette zero voltage was defined in the beginning of the experiment, measured using a flowing $3 \mathrm{M}$ $\mathrm{KCl}$ electrode as described by Neher (1992).

The external solution was standard ACSF for current-clamp experiments and ACSF with $500 \mathrm{~nm}$ tetrodotoxin (TTX) for voltage-clamp experiments. For some experiments testing the effect of iberiotoxin and guangxitoxin, $1 \mathrm{mg} / \mathrm{ml}$ bovine serum albumin (BSA) was added to both control and test solutions to prevent binding of toxins to the tubing of the perfusion system. When BSA was added to background solutions, we used an unbubbled ACSF solution in which 5 mM HEPES was added for additional buffering ( $\mathrm{pH}$ of "modified" ACSF adjusted to 7.4). All compounds were purchased from Sigma-Aldrich except for guangxitoxin-1E (GxTX-1E), which was purchased from Tocris Bioscience.

Slice experiments were done at $34 \pm 1^{\circ} \mathrm{C}$.

\section{Preparation of acutely dissociated dopamine cells}

Dissociated dopamine neurons were prepared from 13- to 19-d-old male and female mice. After isoflurane anesthesia, mice were decapitated, and the brain was quickly removed into ice-cold solution containing the following (in mM): $110 \mathrm{NaCl}, 2.5 \mathrm{KCl}, 10$ HEPES, 25 glucose, 75 sucrose, $7.5 \mathrm{MgCl}_{2}, \mathrm{pH}$ adjusted to 7.4 with $\mathrm{NaOH}$, and bubbled with $95 / 5 \%$ $\mathrm{O}_{2} / \mathrm{CO}_{2}$. In the same solution, $200 \mu \mathrm{m}$ coronal slices were cut using a vibratome (DSK model DTK-1000; Dosaka). The substantia nigra was dissected out of each slice and rinsed in dissociation solution containing the following (in mM): $82 \mathrm{Na}_{2} \mathrm{SO}_{4}, 30 \mathrm{~K}_{2} \mathrm{SO}_{4}, 5 \mathrm{MgCl}_{2}, 10$ glucose, 10 HEPES, $\mathrm{pH}$ adjusted to 7.4 with $\mathrm{NaOH}$.

Following dissection, the pieces of the $\mathrm{SNc}$ were incubated for 7-8 min at $34^{\circ} \mathrm{C}$ in $3 \mathrm{mg} / \mathrm{ml}$ protease XXIII (Sigma Life Science) dissolved in dissociation solution. After enzymatic treatment, the tissue pieces were rinsed in ice-cold dissociation solution containing $1 \mathrm{mg} / \mathrm{ml}$ trypsin inhibitor and $1 \mathrm{mg} / \mathrm{ml} \mathrm{BSA}$, where they were stored until immediately before recording. Cells were used within $8 \mathrm{~h}$ of dissection. Just before recording, chunks of tissue were gently triturated in dissociation solution using a fire-polished Pasteur pipette to free individual cells. The resulting suspension was dispersed into the recording chamber. The cells were allowed to settle for 10-15 min, and the recording chamber was then flooded with Tyrode's solution.

Recordings were made both from mice expressing eGFP under control of the tyrosine hydroxylase promoter (Sawamoto et al., 2001; kindly provided by Dr Kazuto Kobayashi of Fukushima Medical University, Fukushima City, Japan), and from wild-type littermates or from wildtype Swiss Webster mice. In wild-type mice, dopaminergic neurons could be identified by their large size, large A-type potassium current $\left(I_{\mathrm{A}}\right)$ currents, and pacemaking at low frequencies. No difference was evident between mice with labeled or unlabeled neurons in properties of iberitoxin- or paxilline-sensitive current or guangxitoxin-1E-sensitive current or in the effects of the toxins on firing. 
Electrophysiologic recordings with dissociated neurons

Internal solution contained the following (in mм): 122 K-methanesulfonate, $9 \mathrm{NaCl}, 9$ HEPES, 0.18 EGTA, $0.036 \mathrm{CaCl}_{2}, 0.27 \mathrm{MgCl}_{2}, 4$ MgATP, 14 creatine phosphate (Tris salt), and 0.3 GTP (Tris salt), pH 7.4.

Standard external solution was Tyrode's solution containing the following (in $\mathrm{mM}$ ): 151 $\mathrm{NaCl}, 10$ HEPES, 13 glucose, $1.5 \mathrm{CaCl}_{2}, 1$ $\mathrm{MgCl}_{2}, 3.5 \mathrm{KCl}, \mathrm{pH}$ adjusted to 7.4 with $\mathrm{NaOH}$. Experiments to define kinetics of BK and Kv2 currents used paxilline or guangxitoxin-1E on a background of $1 \mu \mathrm{M}$ TTX. In some experiments, we followed application of paxilline and guangxitoxin-1E with a solution designed to block all potassium currents. This solution contained the following (in mM): 155 TEA, 10 HEPES, 13 glucose, 1.5 $\mathrm{CaCl}_{2}, 1 \mathrm{MgCl}_{2}, 10$ 4-aminopyridine, with 1 $\mu \mathrm{M}$ AmmTx3 (Vacher et al., 2002), and $1 \mu \mathrm{M}$ TTX.

Recording pipettes were pulled from borosilicate glass (VWR International) using a Sutter Instruments P-97 horizontal puller, and wrapped with Parafilm to reduce pipette capacitance. When filled with internal solution, typical pipette resistances ranged from 1 to 3 $\mathrm{M} \Omega$. Data have been corrected for a $-8 \mathrm{mV}$ liquid junction potential between the pipette solution and the Tyrode's solution in which current zero was defined.

After a gigaohm seal and whole-cell configuration were established, the cell was lifted off the bottom of the recording chamber and placed in front of an array of quartz fiber flow pipes $(250 \mu \mathrm{m}$ internal diameter, $350 \mu \mathrm{m}$ external diameter) glued onto an aluminum rod whose temperature was controlled by resistive heating elements and a feedback-controlled temperature controller (TC-344B, Warner Instruments). With the aluminum rod maintained at $38^{\circ} \mathrm{C}$, solution exiting from the flow pipes at the location of the cell was measured at $37^{\circ} \mathrm{C}$. Solutions were changed (in $\sim 1 \mathrm{~s}$ ) by moving the cell from one pipe to another. To isolate BK currents, we subtracted currents immediately before and after applying $150 \mathrm{~nm}$ iberiotoxin or $300 \mathrm{~nm}$ paxilline (Zhou and Lingle, 2014). To isolate Kv2 currents, we subtracted currents immediately before and after applying $100 \mathrm{~nm}$ guangxitoxin-1E (Herrington et al., 2006; Herrington, 2007; Liu and Bean, 2014).

Whole-cell recordings were performed using an Molecular Devices Multiclamp 700B amplifier, a Digidata 1322A A/D converter (Molecular Devices), and pCLAMP9.2 software (Molecular Devices). For voltageclamp experiments, series resistance was compensated $70-90 \%$ using the amplifier circuitry. Signals were filtered at $10 \mathrm{kHz}$ and sampled at 10 or 20 $\mu \mathrm{s}$ (and in some cases, additionally digitally filtered during analysis with a low-pass filter corresponding to a 4-pole Bessel filter with a corner frequency of $2 \mathrm{kHz}$ ).

Analysis. Data analysis was done using IgorPro v6.126 (Wavemetrics), using DataAccess (Bruxton) to read pClamp files into Igor. In voltageclamp experiments, capacitative transients were reduced by the electronic capacitance compensation in the amplifier circuit and any remaining capacity transients were corrected during analysis using small $(5-10 \mathrm{mV})$ steps in a hyperpolarized range (negative to -70 $\mathrm{mV}$ ) to define linear capacitance and leak currents and then subtracting appropriately scaled currents. In some cases, correction for capacity transients was imperfect as a result of amplifier saturation for large voltage steps, and 100-200 $\mu$ s of the current record is blanked in the displayed records. to zero current. $34^{\circ} \mathrm{C}$.
B

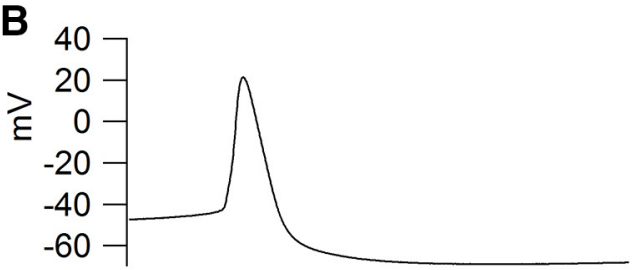

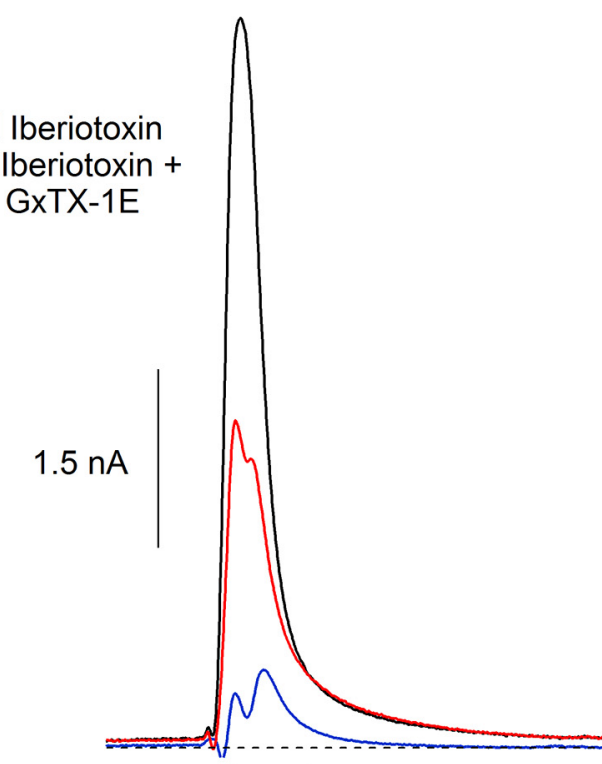

$4 \mathrm{~ms}$

Figure 1. BK and Kv2 currents in a dopamine neuron recorded in brain slice. $\boldsymbol{A}$, Outward currents in a dopamine neuron evoked by depolarization from -63 to $+2 \mathrm{mV}$ in control (black) and after application of $150 \mathrm{~nm}$ iberiotoxin (red) and $100 \mathrm{~nm}$ Capacitative currents were reduced by the electronic capacitance compensation in the amplifier circuit and remaining capacity current was corrected during analysis using a step from -63 to $-68 \mathrm{mV}$ to define the capacity current. Dashed lines correspond

Action potential clamp. In action potential clamp experiments, we used typical action potential waveforms previously recorded during spontaneous firing in each preparation and temperature (brain slice at $34^{\circ} \mathrm{C}$ or dissociated cells at $37^{\circ} \mathrm{C}$ ). We isolated ionic currents evoked by the action potential from capacitative currents (expected to be equal and opposite; cf. Taddese and Bean, 2002) by eliminating capacitative currents, first by using electronic capacitance nulling in the amplifier circuit during recording and then by removing any remaining capacitative current during analysis, applying a point-by-point capacity correction using a scaled capacity transient, determined by a $5 \mathrm{mV}$ hyperpolarizing pulse.

Analysis of evoked firing. Frequency-current $(f-I)$ relationships for evoked firing were determined by injecting $200 \mathrm{~ms}$ or $1 \mathrm{~s}$ current steps with amplitudes increasing by $20 \mathrm{pA}$, typically up to a maximum of 300-320 pA (or less if cells entered depolarization block for smaller currents). The initial frequency of firing was calculated from the first three spikes. The slope of the $f-I$ relationship was calculated from a linear fit for the data from zero to $160 \mathrm{pA}$ (or to the maximum current injected if less), for which the $f-I$ relationship was approximately linear.

\section{Choice of blockers and concentrations}

We used both iberiotoxin and paxilline to inhibit BK channels. Paxilline inhibits BK channels with a half-blocking concentration of $\sim 10 \mathrm{nM}$ (Knaus et al., 1994) regardless of the presence or identity of $\beta$ subunits (Hu et al., 2001; Wang et al., 2014), whereas BK channels containing $\beta 4$ subunits are essentially insensitive to iberiotoxin (Meera et al., 2000; Wang et al., 2014). Because we wanted to quantify all BK current present, 
A Control $(2.5 \mathrm{~Hz})$

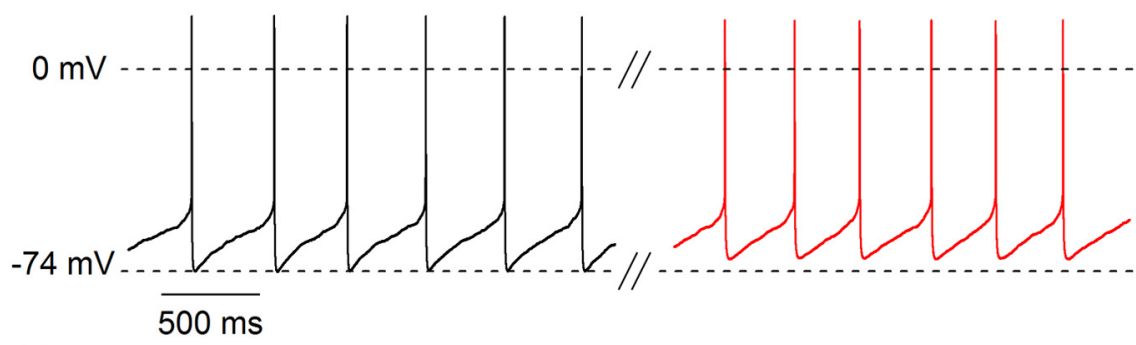

B
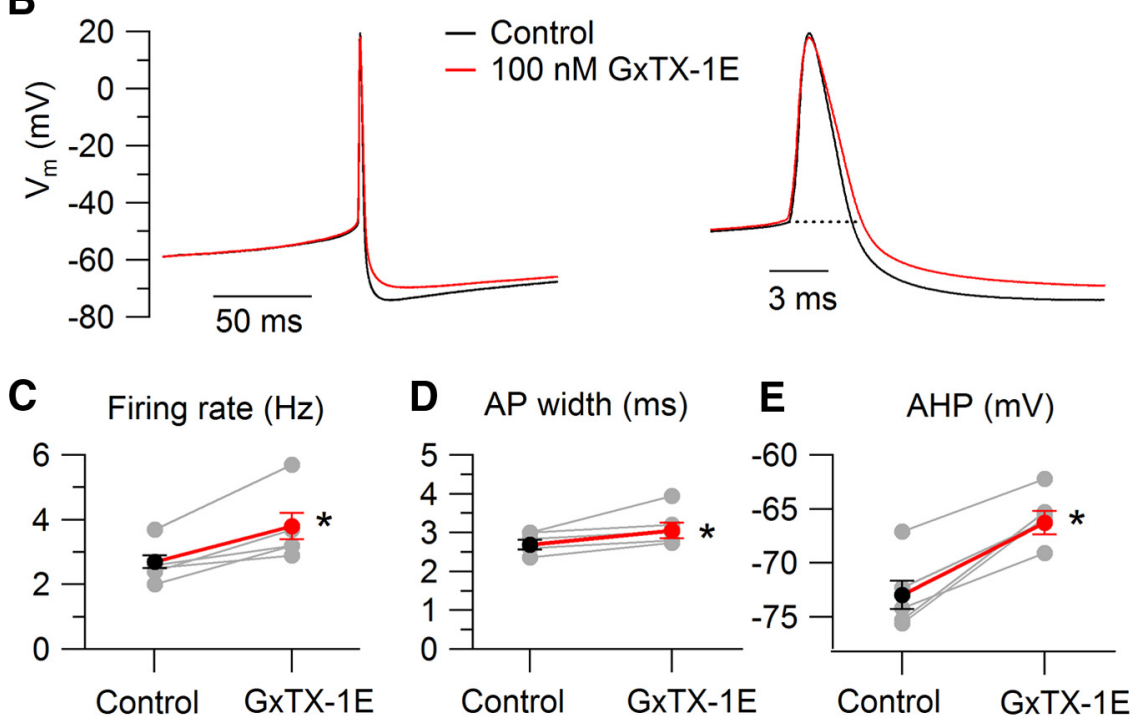

Figure 2. Effect of Kv2 inhibition on spontaneous firing and action potential shape in brain slice. $\boldsymbol{A}$, Spontaneous pacemaking at $34^{\circ} \mathrm{C}$ in control (left, black) and after application of $100 \mathrm{~nm}$ GXTX-1E (right, red). $\boldsymbol{B}$, Signal-averaged action potentials in control (black) and $100 \mathrm{~nm}$ GxTX-1E (red). Waveforms on the right are shown on an expanded timescale. Action potentials were signalaveraged over six to eight firing cycles by aligning at the peak. C, Collected results for effect of GXTX-1E on firing rate in six neurons. Data from individual cells are in gray; black and red symbols are mean values \pm SEM for control and GXTX-1E, respectively. $\boldsymbol{D}$, Collected results for effect of GXTX-1E on action potential width (measured at the threshold voltage, as illustrated in $\boldsymbol{B}$ ) in six neurons. $\boldsymbol{E}$, Collected results for effect of GXTX-1E on the most negative voltage reached after the action potential (AHP) in six neurons. Asterisks indicate significance at 0.05 .

we used $300 \mathrm{~nm}$ paxilline in most experiments with dissociated cells. However, in experiments in brain slice, we found that paxilline inhibition was slow to develop, probably reflecting loss of the relatively hydrophobic molecule into the large volume of tissue. Iberiotoxin inhibition reached steady-state more quickly, likely because of lack of partition into cells. Therefore, most slice experiments were done with $150 \mathrm{~nm}$ iberiotoxin. We also tested $150 \mathrm{~nm}$ iberiotoxin on a smaller number of dissociated neurons and saw similar amount of inhibition $(49 \pm 9 \%, n=7)$ as produced by paxilline (53 $\pm 3 \%, n=23$ ) for action potential-evoked outward current, which was also similar to the reduction we saw with iberiotoxin in slice experiments ( $59 \pm 9 \%, n=7)$. Therefore, it seems likely that most or all of the BK current in dopaminergic neurons is iberiotoxin-sensitive "type I" current from channels lacking the $\beta 4$ subunit (cf. Wang et al., 2014). The fast activation kinetics (see Fig. $6 D, E$ ) are also consistent with type-I BK current (Jaffe et al., 2011; Wang et al., 2014).

Previous experiments have shown that paxilline inhibits BK channels with a high degree of selectivity (Knaus et al., 1994). Iberiotoxin also is highly selective for BK channels (Galvez et al., 1990). Although it is difficult to be completely sure that selectivity established using heterologously expressed channels carries over to native neuronal channels, it was very clear in our experiments that neither iberiotoxin nor paxilline inhibited Kv2 current significantly, because neither had any significant blocking effect on the slow tail current at -48 or $-68 \mathrm{mV}$, which was blocked effectively by GxTX-1E (Figs. 1A, Fig. 6A). GxTX-1E was previously found to have no blocking effect on BK channels (Herrington et al.,
2006). However, GxTX-1E does produce weak inhibition of $I_{\mathrm{A}}$, so we used a concentration of 100 nM which in previous experiments was found to produce nearly maximal inhibition of neuronal Kv2 channels while inhibiting $I_{\mathrm{A}}$ only slightly (Liu and Bean, 2014).

Data are presented as mean \pm SEM. Significance of changes in parameters was assessed by the nonparametric Mann-Whitney test for unpaired data and the Wilcoxon signed rank test for paired data. For $N \geq 10$, two-tailed $p$ values were calculated; for $N<10$, nondirectional significance limits are stated based on the small-sample critical values table.

\section{Results}

BK and Kv2 channels carry large depolarization-activated currents in dopaminergic SNc neurons

Single-channel currents through large conductance calcium-activated potassium (BK) channels have been described in SNc dopaminergic cells (Su et al., 2010; Ramírez-Latorre, 2012), but the size and kinetics of macroscopic BK current in dopaminergic neurons are unknown. To determine the possible contribution of BK channels to overall depolarizationactivated potassium currents in dopaminergic SNc neurons, we performed voltage-clamp experiments, first in brain slice and then in dissociated neurons. We found that BK channels carry a substantial fraction of total depolarization-activated potassium current in both preparations. Figure 1 shows a recording from a dopaminergic neuron in a brain slice. Application of the selective $\mathrm{BK}$ inhibitor iberiotoxin (150 nM) inhibited approximately one-third of the current activated by a step from -63 to $+2 \mathrm{mV}$. This result was typical. In collected results, $150 \mathrm{~nm}$ iberiotoxin inhibited current evoked by a step from -63 to $+2 \mathrm{mV}$ by $38 \pm 6 \%$ $(n=7)$.

Another likely candidate for contributing to overall voltageactivated potassium current is Kv2-mediated current. Kv2 channels are widely expressed in the somatodendritic regions of most central neurons (Trimmer, 1991) and have been recently shown to be present in midbrain dopamine neurons by immunocytochemistry (Dufour et al., 2014). We therefore tested whether the voltage-activated outward current remaining after BK inhibition included Kv2 current, using $100 \mathrm{~nm} \mathrm{GxTX-1E,} \mathrm{a} \mathrm{spider} \mathrm{venom} \mathrm{peptide} \mathrm{that} \mathrm{is} \mathrm{a} \mathrm{fairly}$ potent and selective Kv2 inhibitor (Herrington et al., 2006; Herrington, 2007). In a previous study on native potassium channels in mammalian neurons, $100 \mathrm{~nm}$ GxTX-1E was found to inhibit Kv2 channels nearly completely with little effect on other types of potassium channels (Liu and Bean, 2014).

A fairly large fraction of the depolarization-evoked outward current in SNc cells in slices was sensitive to GxTX-1E. In the experiment in Figure 1A, application of 100 nM GxTX (in the continued presence of iberiotoxin) inhibited another large fraction of current, comprising $\sim 48 \%$ of the initial current evoked by the step to +2 $\mathrm{mV}$. In collected results, $100 \mathrm{~nm}$ GxTX-1E inhibited $36 \pm 6 \%$ of the initial control current $(n=7)$. 
The components of current inhibited by iberiotoxin and GxTX-1E had different kinetics and voltage dependence, as was most evident by the currents during a step to $-48 \mathrm{mV}$ following the $50 \mathrm{~ms}$ step to +2 $\mathrm{mV}$. Iberiotoxin had no effect on the sizeable tail current at $-48 \mathrm{mV}$, suggesting that $\mathrm{BK}$ channels deactivate rapidly and completely at $-48 \mathrm{mV}$. However, GxTX-1E strongly inhibited the slowly decaying current at $-48 \mathrm{mV}$ and also completely inhibited a remaining tail current at $-63 \mathrm{mV}$, suggesting that this slowly deactivating component of current is carried largely by $\mathrm{Kv} 2$ channels. In collected results, the current at $-48 \mathrm{mV}$ was nearly untouched by iberiotoxin (reduction of $5 \pm 4 \%, n=7$ ) and was inhibited $69 \pm 4 \%$ by $100 \mathrm{~nm}$ GxTX-1E $(n=7)$. The slow deactivation of Kv2 current fits well with previous results obtained with both cloned and native Kv2 channels (McCrossan et al., 2003; Misonou et al., 2005; Liu and Bean, 2014).

To explore whether BK or Kv2 channels activate rapidly enough to be activated during action potentials, we examined activation of potassium current during action potential waveforms applied as the voltage command. The action potential waveform used as voltage command was previously recorded during spontaneous firing in a different dopaminergic neuron in brain slice studied with the same internal and external solutions (except for omission of tetrodotoxin). The action potential waveform was applied in the same sweep as the voltage steps, so we could compare the block of BK and Kv2 currents during the same application of iberiotoxin and GxTX-1E. To isolate ionic current, we eliminated most capacitative current using the capacity-correction circuit in the amplifier and then additionally corrected any remaining capacitative current by applying a point-by-point capacity correction on the current records, using a $5 \mathrm{mV}$ hyperpolarizing step to define remaining capacity current. The inward sodium current evoked during the rising phase of the action potential was blocked by TTX, leaving a large outward current during the repolarizing phase of the spike. As shown in Figure 1B, both iberiotoxin and GxTX-1E inhibited a substantial fraction of this outward current. In collected results, $150 \mathrm{~nm}$ iberiotoxin inhibited peak action potential-evoked

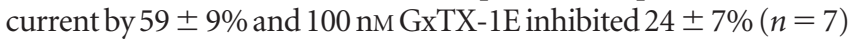
of the initial peak current. The currents blocked by iberiotoxin and GxTX-1E had different kinetics, with GxTX-1E inhibiting a longerlasting component of current during the late falling phase and afterhyperpolarization of the action potential. This fits well with the slowly deactivating component of Kv2 current evident in the tail currents in Figure $1 A$.

Because the component of GxTX-1E-sensitive current flowing late in the spike waveform is not reflected in the reduction of peak spike-evoked current, we also quantified the effects of BK and Kv2 channel inhibition on integrated outward current evoked by the spike. Iberiotoxin inhibited integrated outward current
$150 \mathrm{nM}$ Iberiotoxin $(4.0 \mathrm{~Hz})$
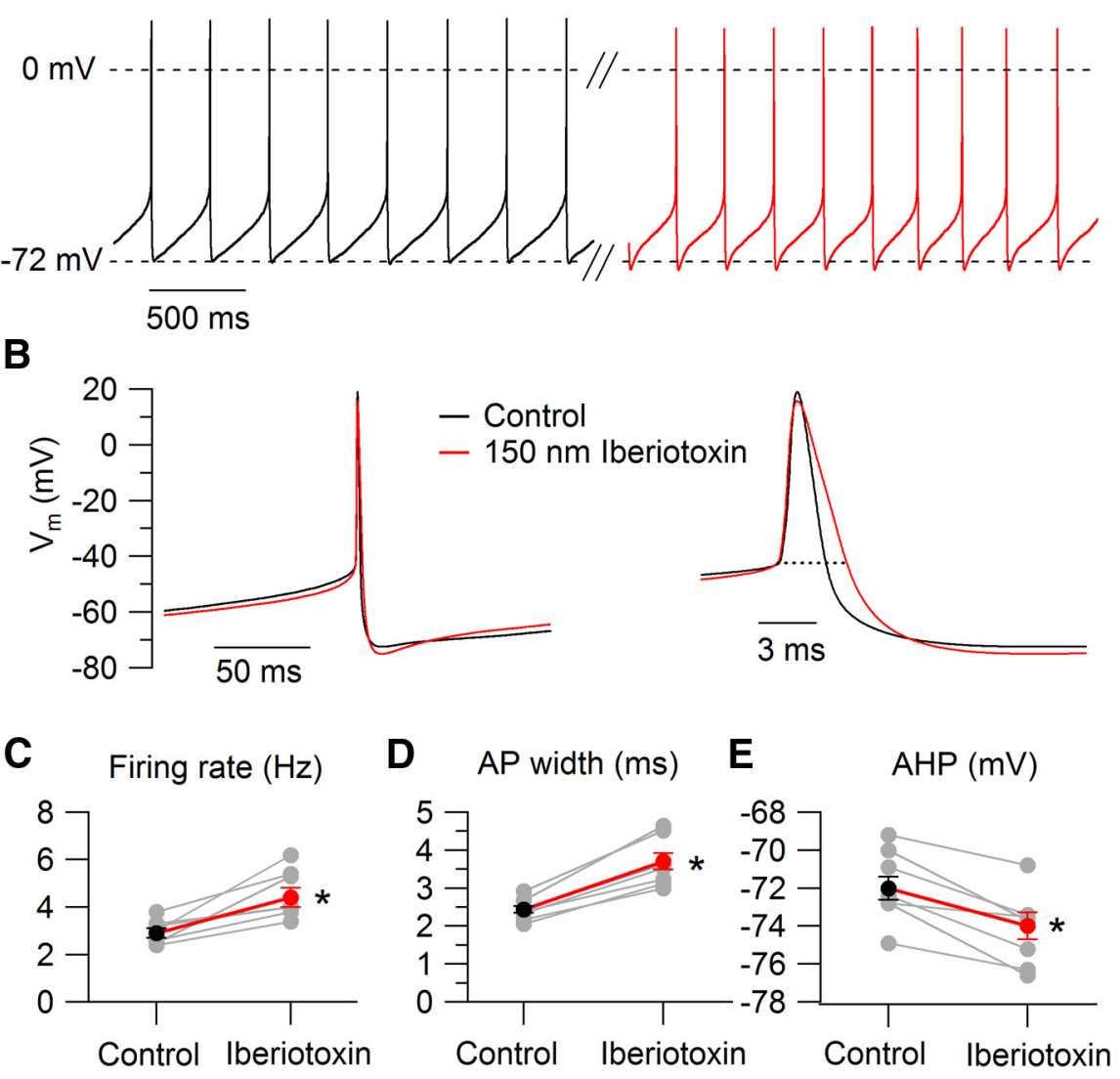

Figure 3. Effect of BK inhibition on spontaneous firing and action potential shape in brain slice. $\boldsymbol{A}$, Spontaneous pacemaking at ack) and $150 \mathrm{~nm}$ iberiotoxin (red). Waveforms on the right are shown on an expanded timescale. Action potentials were in $\boldsymbol{B}$ ) in eight neurons. $\boldsymbol{E}$, Collected results for effect of iberiotoxin on the most negative voltage reached after the action potential (AHP) in eight neurons. Asterisks indicate significance at 0.01 .

by $48 \pm 9 \%$ and GxTX-1E inhibited integrated current by $37 \pm 7 \%(n=7)$.

It is important to note that the total potassium current flowing during the action potential is larger than the net outward current, because inward calcium current also flows during the falling phase of the action potential (Puopolo et al., 2007). Therefore, the fractional reduction of the net outward current is larger than fractional reduction of total potassium current. Nevertheless, the results make it clear that both BK and Kv2 channels are activated during spike waveforms and that each contributes a sizeable fraction of overall potassium current during the spike repolarization, with Kv2 channels contributing a longer-lasting current. The significant contribution of Kv2 channels to action potential repolarization despite their relatively slow activation kinetics is consistent with previous results in other neuronal types including sympathetic neurons (Malin and Nerbonne, 2002; Liu and Bean, 2014), auditory neurons of the ventral and medial nuclei of the trapezoid body (Tong et al., 2013), and hippocampal CA1 pyramidal neurons (Liu and Bean, 2014).

\section{Differential effects of $\mathrm{BK}$ and $\mathrm{Kv} 2$ inhibition on action potential shape}

We next examined the effects of inhibiting Kv2 and BK current on action potential and firing patterns in current-clamp ex- 
A Control
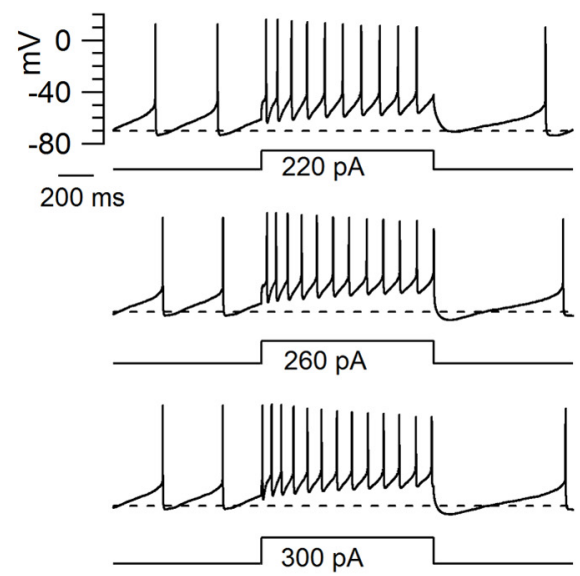

B

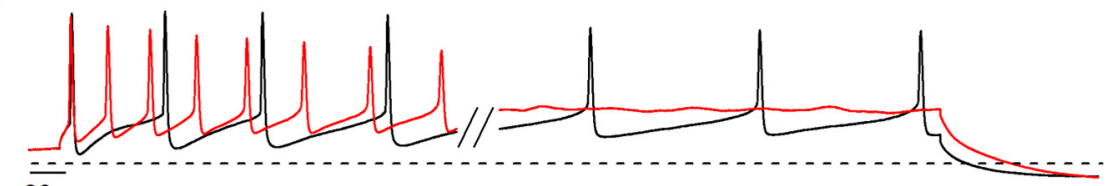

$20 \mathrm{~ms}$

C

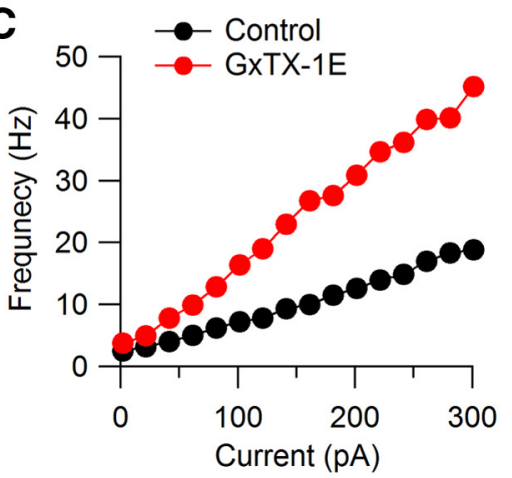

Figure 4. Effect of Kv2 inhibition on evoked firing of dopamine neurons in brain slice. $A$, Burst-like activity in response to current injections in control (left) and after application of $100 \mathrm{~nm}$ GXTX-1E (right). Dashed lines at $-70 \mathrm{mV}$. $\boldsymbol{B}$, Superimposed voltage traces for injection of $300 \mathrm{pA}$ at the beginning (left) and end (right) of a $1 \mathrm{~s}$ period of current injection. Dashed line at $-70 \mathrm{mV}$. C, Firing frequency of first three spikes as a function of injected current in control (black) and with GxTX-1E (red) for the cell in $\boldsymbol{A}$ and $\boldsymbol{B}$. D, Collected data for effect of $100 \mathrm{~nm}$ GXTX-1E on slope of frequency-current relationship. Slope was determined by linear fit from 0 to $160 \mathrm{pA}$. Gray symbols show data for each of six cells. Black and red symbols are mean \pm SEM in control and in $100 \mathrm{~nm} \mathrm{GxTX}-1 \mathrm{E}$, respectively. $34^{\circ} \mathrm{C}$. Asterisk indicates significance at 0.05 .

increase in pacemaking frequency, from $2.9 \pm 0.2 \mathrm{~Hz}$ in control to $4.4 \pm 0.4 \mathrm{~Hz}$ after application of $150 \mathrm{~nm}$ iberiotoxin ( $n=8$; significant at 0.01 ). Surprisingly, however, inhibiting BK channels was accompanied by a paradoxical increase in the afterhyperpolarization (Fig. 3) rather than the reduction intuitively expected from inhibition of a spikeevoked potassium conductance. Iberiotoxin resulted in an increase of the hyperpolarization by an average of $-2.1 \pm 0.5 \mathrm{mV}$, from $-71.9 \pm 0.6$ to $-74.0 \pm 0.7 \mathrm{mV}(n=8$; significant at 0.01 ). As will be discussed, further experiments showed that this effect likely arises from increased activation of Kv2 current during the action potential.

\section{Differential effects of BK and Kv2 inhibition on evoked firing}

Although inhibiting BK channels or Kv2 channels had similar effects to modestly increase the rate of pacemaking, they had very different effects on firing evoked by current injection. Figure 4 illustrates the effect of GxTX-1E on evoked firing. There were two main effects of Kv2 inhibition: faster initial firing, especially for larger current injections, but also an increased propensity to enter depolarization block (Fig. $4 A$, right). In control conditions, four of six cells continued to fire throughout a $1 \mathrm{~s}$ stimulation for current injections up to $300 \mathrm{pA}$, whereas the other two entered depolarization block during injections of 200 and 220 pA. After addition of GxTX-1E, five of six cells entered depolarization block for current injections of between 140 and 300 pA. The entry into depolarization block was preceded by increasingly depolarized troughs between spikes (Fig. $4 A, B$ ) and by progressively smaller spikes, presum-

periments. Figure 2 illustrates the effect of Kv2 inhibition by GxTX-1E on action potentials during spontaneous pacemaking. GxTX-1E decreased the rate of spike repolarization, especially in the late phase of repolarization, and resulted in a reduction of the afterhyperpolarization following the spike. Spike width (measured at spike threshold to capture the effects on the late phase of repolarization) increased from $2.69 \pm 0.12$ $\mathrm{ms}$ in control to $3.05 \pm 0.20 \mathrm{~ms}$ with $100 \mathrm{nM} \mathrm{GxTX}-1 \mathrm{E}(n=6$; significant at 0.05 ). The afterhyperpolarization (measured at the trough following the action potential) depolarized by an average of $6.7 \pm 1.0 \mathrm{mV}$, from $-73.0 \pm 1.3$ to $-66.3 \pm 1.1 \mathrm{mV}$ ( $n=6$; significant at 0.05 ). These effects on spike shape were accompanied by an increase in pacemaking frequency, from $2.7 \pm 0.2$ to $3.8 \pm 0.4 \mathrm{~Hz}(n=6$; significant at 0.05$)$.

Inhibiting BK channels also resulted in an increase in action potential width, from $2.44 \pm 0.09 \mathrm{~ms}$ in control to $3.71 \pm$ $0.21 \mathrm{~ms}$ in $150 \mathrm{~nm}$ iberiotoxin $(n=8$; significant at 0.01$)$. Like inhibition of Kv2 current, BK inhibition produced a modest ably reflecting inactivation of sodium channels as a consequence of the more depolarized troughs.

Figure $4 C$ shows the effect of $\mathrm{Kv} 2$ channel block on the initial firing frequency, calculated from the first three spikes. Firing frequency was increased for all levels of current injection, and the slope of the relationship between frequency and injected current ( $f-I$ slope) was increased. This result was typical. In collected results, the slope of the $f-I$ curve increased more than twofold, from $0.079 \pm$ $0.011 \mathrm{~Hz} / \mathrm{pA}$ in control to $0.179 \pm 0.016 \mathrm{~Hz} / \mathrm{pA}$ after application of GxTX-1E (Fig. 4D; $n=6$, significant at 0.05 ).

In striking contrast, $\mathrm{BK}$ inhibition did not increase the slope of the $f-I$ curve (Fig. 5). In fact, in four of eight cells tested, the slope of the $f-I$ curve decreased slightly after BK inhibition of iberiotoxin, sometimes accompanied by a decrease in the rate of firing induced by strong depolarizations (Fig. $5 B, C$ ). In collected results, the slope of the $f-I$ curve was $0.098 \pm 0.007 \mathrm{~Hz} / \mathrm{pA}$ in control and $0.091 \pm$ $0.005 \mathrm{~Hz} / \mathrm{pA}$ after addition of $150 \mathrm{~nm}$ iberiotoxin $(n=8)$. 
Characterization of $\mathrm{BK}$ and $\mathrm{Kv} 2$ current in acutely dissociated neurons

To better understand the different effects of Kv2 and BK current inhibition of spike shape and firing patterns, we turned to experiments in acutely dissociated neurons. This preparation allows faster and more accurate voltage-clamp and better definition of channel kinetics, as well as rapid application of blockers. Very similar to the results in brain slice experiments, we found that BK and Kv2 channels each contribute large components of the overall voltage-activated potassium current in acutely dissociated neurons. Figure 6 shows the effect of cumulative addition of the BK inhibitor paxilline (300 nM) followed by GxTX-1E (100 nM) on currents evoked by a step from -68 to $+22 \mathrm{mV}$. In collected results, $300 \mathrm{~nm}$ paxilline inhibited outward current at the end of a $50 \mathrm{~ms}$ step from -58 or -68 to $-8 \mathrm{mV}$ by $42 \pm$ $4 \%(n=12)$ and $100 \mathrm{~nm}$ GxTX-1E inhibited by $36 \pm 3 \%$ (relative to initial control current). The GxTX-1E-sensitive current had a slowly decaying tail current (Fig. 6A, inset), with an average time constant of deactivation of $8.1 \pm 0.7 \mathrm{~ms}$ at $-68 \mathrm{mV}$ ( $n=20)$. In contrast, the paxillinesensitive current deactivated too rapidly to be quantified, with nearly complete deactivation at $-68 \mathrm{mV}$ within $\sim 500 \mu \mathrm{s}$.

To characterize the voltage dependence of $\mathrm{BK}$ and $\mathrm{Kv} 2$ currents, we constructed conductance-voltage relationships for the two components of current. The component carried by BK channels was reasonably well-fit by a Boltzmann function (Fig. 6B), with an average midpoint of $-14.5 \pm 1.2 \mathrm{mV}$, a slope factor of $9.2 \pm 0.5 \mathrm{mV}$, and an average magnitude of $26.6 \pm 4.7 \mathrm{nS}(n=13)$. The component carried by Kv2 current activated with a slightly more depolarized voltage dependence (Fig. 6C), with an average midpoint of $-8.6 \pm 1.2 \mathrm{mV}$, a slope factor of $10.4 \pm 0.2 \mathrm{mV}$, and had a larger average magnitude of $36.2 \pm 5.0 \mathrm{nS}(n=13)$. The voltage dependence of Kv2 current in dopaminergic neurons is generally similar to the voltage dependence of native Kv2 current previously determined in neocortical pyramidal neurons (midpoint $-3 \mathrm{mV}$, slope factor $10.5 \mathrm{mV}$; Guan et al., 2007), globus pallidus neurons (midpoint $-18 \mathrm{mV}$, slope factor $7 \mathrm{mV}$; Baranauskas et al., 1999), and hippocampal CA1 neurons (midpoint of $-11 \mathrm{mV}$ and slope factor of $10 \mathrm{mV}$; Liu and Bean, 2014).

We took advantage of the fast voltage-clamp possible in the acutely dissociated neurons to characterize the kinetics of BK and Kv2 current (Fig. 6D). BK current activated much more rapidly than Kv2 current at all voltages. In addition, the kinetics of BK current had relatively little voltage dependence, whereas the activation speed of Kv2 current increased with larger depolarizations (but was always slower than BK current). Quantified as the time to half-maximal current, BK current half-activated in $0.99 \pm 0.13 \mathrm{~ms}$ at $-28 \mathrm{mV}$, in $0.87 \pm 0.28 \mathrm{~ms}$ at $+2 \mathrm{mV}$ and in
Control

$150 \mathrm{nM}$ Iberiotoxin
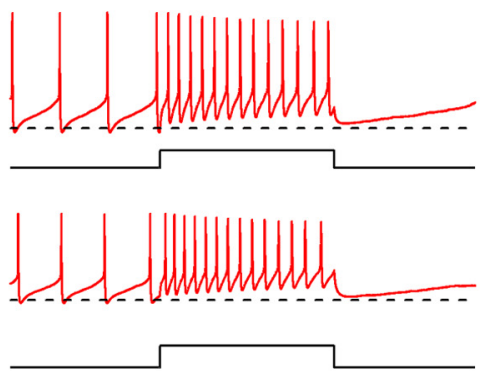

$200 \mathrm{pA}$

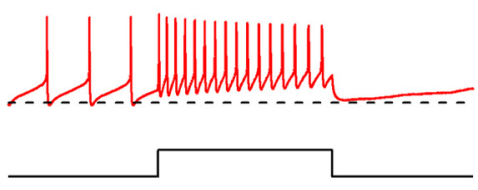

$240 \mathrm{pA}$

B

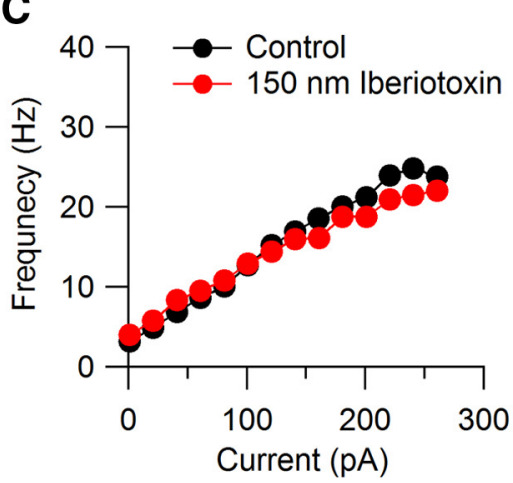

D

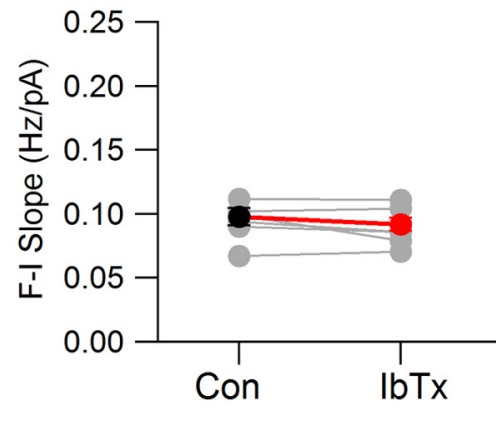

Figure 5. Effect of BK inhibition on evoked firing in brain slice. $\boldsymbol{A}$, Burst-like activity in response to current injections in control of frequency-current relationship. Slope was determined by linear fit from 0 to $160 \mathrm{pA}$. Gray symbols show data for each of eight cells. Black and red symbols are mean \pm SEM in control and in $150 \mathrm{~nm}$ iberiotoxin, respectively. $34^{\circ} \mathrm{C}$.

$0.87 \pm 0.28 \mathrm{~ms}$ at $+22 \mathrm{mV}$, whereas $\mathrm{Kv} 2$ current half-activated in $5.1 \pm 1.9 \mathrm{~ms}$ at $-28 \mathrm{mV}$, in $3.5 \pm 0.5 \mathrm{~ms}$ at $+2 \mathrm{mV}$ and in $2.5 \pm$ $0.2 \mathrm{~ms}$ at $+22 \mathrm{mV}$. Thus, KV2-mediated current requires slightly larger depolarizations than BK current to activate and activates threefold to fivefold more slowly over the voltage range of an action potential.

\section{Action potential-evoked BK and Kv2 currents in dissociated neurons}

We next examined directly the time course of activation of BK and Kv2 channels during the action potential with action potential clamp, using a typical action potential waveform recorded during pacemaking activity of an acutely dissociated cell firing spontaneously at $37^{\circ} \mathrm{C}$. Figure 7 shows an example in which we dissected the components of overall potassium current carried by $\mathrm{BK}$ and $\mathrm{Kv} 2$ channels, using $300 \mathrm{~nm}$ paxilline to define BK current and $100 \mathrm{~nm}$ GxTX-1E to define Kv2 current. On average, paxilline reduced the peak outward current evoked by action potential 
A

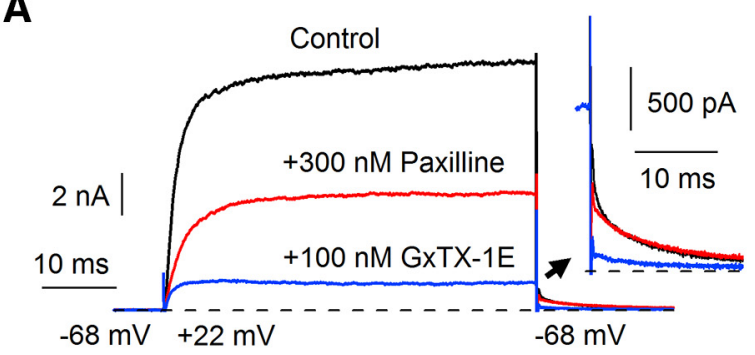

B

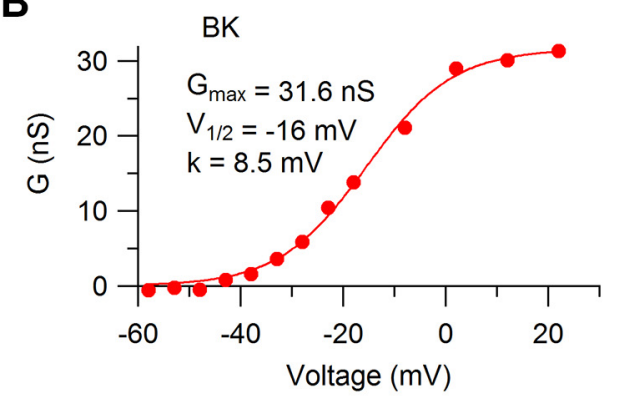

C

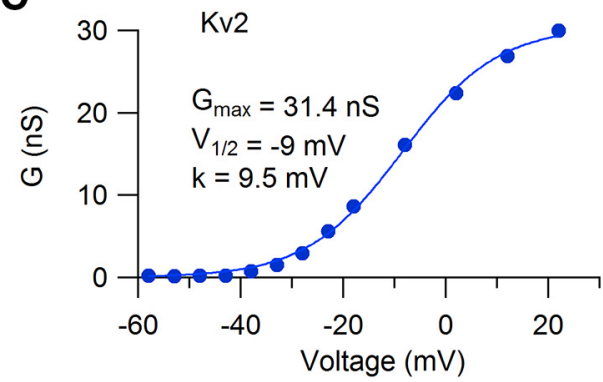

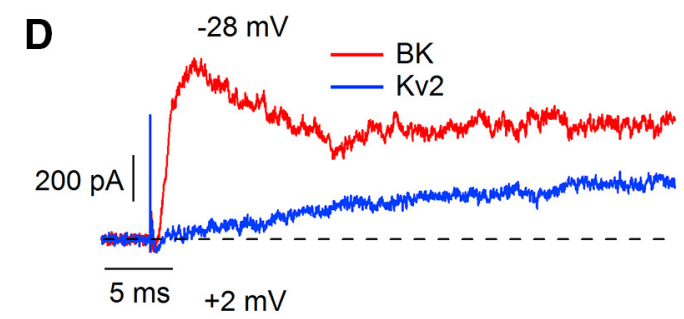

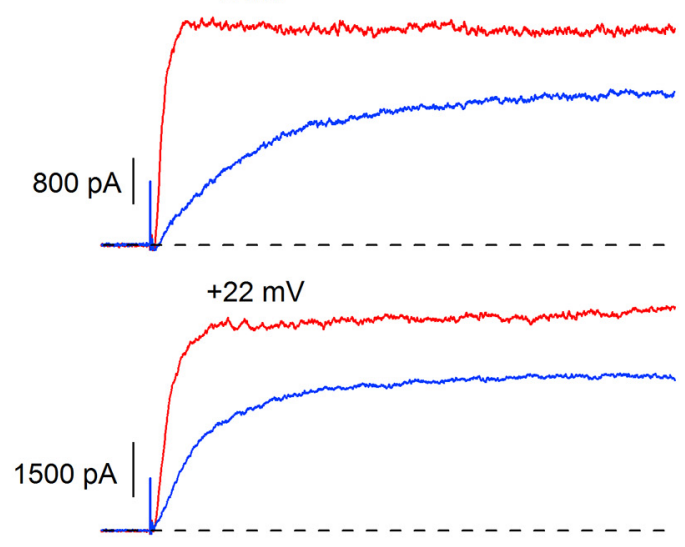

E

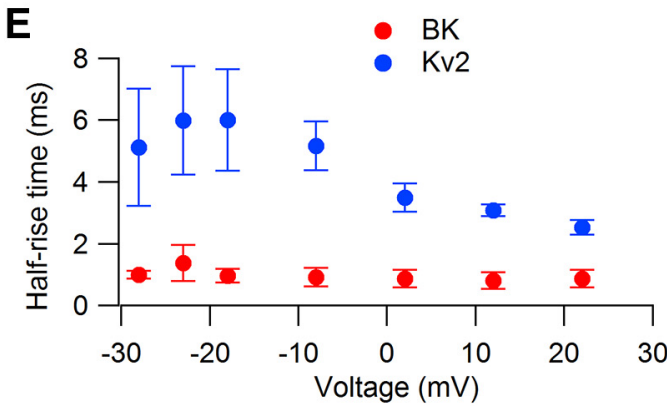

Figure 6. BK and Kv2 currents in acutely dissociated dopamine neurons at $37^{\circ} \mathrm{C}$. $A$, Outward current evoked by voltage steps from $-68 \mathrm{to}+22 \mathrm{mV}$ in control (black), after application of $300 \mathrm{~nm}$ paxilline (red), and after addition of $100 \mathrm{~nm}$ GXTX-1E (blue) in the continuing presence of paxilline. $\boldsymbol{B}$, Conductance-voltage relation of paxilline-sensitive current. $\boldsymbol{C}$, Conductance-voltage relation of GXTX-1E-sensitive current (determined in same cell as $\boldsymbol{B}$ ). $\boldsymbol{D}$, Activation kinetics of paxilline-sensitive and GxTX-1E-sensitive currents at different voltages. $\boldsymbol{E}$, Time to half-maximum current for paxilline-sensitive (red) and GXTX-1E-sensitive current (blue) as a function of voltage. Mean $\pm \mathrm{SEM} ; n=7$.

waveforms by $53 \pm 3 \%(n=23)$, and inhibiting Kv2 channels reduced the peak outward current evoked by action potential waveforms by $45 \pm 5 \%(n=19)$. As noted previously, the total potassium current flowing during the action potential repolarization is larger than the net outward current, because inward calcium current also flows during the action potential repolarization (Puopolo et al., 2007). In the experiment of Figure 7A, we followed the application of paxilline and GxTX-1E by applying a solution designed to inhibit all potassium currents, in which sodium was replaced by $155 \mathrm{~mm}$ TEA, together with $10 \mathrm{~mm}$ 4-aminopyridine and the Kv4-channel blocker AmmTx3 (Vacher et al., 2002; Amendola et al., 2012). This solution blocked additional outward current compared with paxilline and GxTX-1E together, revealing an inward current, likely carried by calcium channels, during the falling phase of the action potential. We cannot be sure that this solution blocked all potassium channels, but the experiment clearly shows that the components of current carried by BK and Kv2 channels are accompanied by additional potassium currents that remain to be identified.

Consistent with the different kinetics of BK and Kv2 currents seen with voltage steps, the BK and Kv2 components of current activated by the action potential had different kinetics. The BK current activated much earlier during the action potential waveform, typically beginning before the peak of the action potential (cf. Petrik et al., 2011). Kv2 current had a longer lag, beginning to activate just after the peak of the action potential and reaching a peak later in the repolarizing phase. In addition, Kv2 current continued to flow longer into the afterhyperpolarization, consistent with the slower deactivation kinetics of Kv2 channels seen with voltage steps. In collected results, BK current reached its peak $0.64 \pm 0.04 \mathrm{~ms}(n=26)$ after the peak of the action potential, whereas Kv2 current reached its peak $0.99 \pm 0.04 \mathrm{~ms}$ after the action potential peak $(n=27 ; p<0.0001)$. The time course of deactivation during the action potential was quantified by measuring the time at which each current decayed to $25 \%$ of its peak value, with time measured relative to the peak of the action potential. The time of decay to $25 \%$ was $1.60 \pm 0.04 \mathrm{~ms}$ after the peak for BK current $(n=26)$ and $2.29 \pm 0.11 \mathrm{~ms}$ after the peak for Kv2 current $(n=27, p<0.0001)$.

The difference in the kinetics of BK and Kv2 channel activation and deactivation during the action potential was seen especially clearly by plotting the conductance from each channel type (Fig. 7, right), illustrating the persistence of the Kv2 conductance into the afterhyperpolarization, when driving force is relatively small. 
We used paxilline to inhibit BK current in dissociated cells because we wanted to measure all BK current, including any channels containing $\beta 4$ subunits, which are not blocked by iberiotoxin (Meera et al., 2000; Wang et al., 2014). In a smaller number of dissociated cells, we tested the effect of iberiotoxin on spikeevoked outward current. Iberiotoxin (150 $\mathrm{nM})$ inhibited $49 \pm 9 \%(n=7)$ of spikeevoked outward current, very similar to the inhibition by $300 \mathrm{~nm}$ paxilline (53 \pm $3 \%, n=23$ ) and also similar to the inhibition by 150 iberiotoxin of spike-evoked current in the slice experiments (59 $\pm 9 \%$ $n=7)$. The comparison suggests that little if any BK current in dopaminergic neurons arises from $\beta 4$-containing channels.

\section{Effects of BK and Kv2 inhibition on action potential shape and evoked firing in dissociated neurons}

Similar to the results in brain slice recordings, inhibiting Kv2 and BK current had very different effects on spike shape and evoked firing in current-clamp experiments using acutely dissociated neurons. As in the brain slice experiments, inhibiting either Kv2 channels or BK channels produced a widening of the action potential, but although inhibition of Kv2 channels reduced the size of the afterhyperpolarization, inhibition of BK channels produced an increase in the afterhyperpolarization (Fig. 8). Inhibiting Kv2 channels with 100 nM GxTX-1E increased spike width from $2.11 \pm 0.12 \mathrm{~ms}$ in control to $3.24 \pm 0.34 \mathrm{~ms}$ with $100 \mathrm{~nm} \mathrm{GxTX}-1 \mathrm{E}(n=15, p=0.0008)$ and shifted the afterhyperpolarization more positive by an average of $5.9 \pm 0.6 \mathrm{mV}$, from $-72.3 \pm 1.0$ to $-66.4 \pm 1.0 \mathrm{mV}(n=$ $15, p=0.0007)$. Inhibiting $\mathrm{BK}$ channels by $300 \mathrm{~nm}$ paxilline increased spike width from $1.96 \pm 0.10 \mathrm{~ms}$ in control to $2.62 \pm$ $0.10 \mathrm{~ms}$ with paxilline $(n=19, p=0.0001)$ and increased the afterhyperpolarization by an average of $-2.6 \pm 0.5 \mathrm{mV}$, from $-72.1 \pm 0.8$ to $-74.7 \pm 0.7 \mathrm{mV}(n=19, p=0.0003)$. Thus, the different effects of Kv2 and BK inhibition on spike shape are very similar in acutely dissociated neurons as for neurons in brain slice.

The contrasting effects of KV2 and BK inhibition on evoked firing were also evident in acutely dissociated neurons (Fig. 9). Just as for the experiments in brain slice, inhibiting Kv2 channels produced an increase in the frequency of evoked firing at the beginning of the current injection, but cells entered depolarization block more readily (Fig. $9 A$ ). The slope of the $f-I$ curve measured from the initial firing frequency increased almost twofold after Kv2 inhibition (Fig. 9B, C), from an average of $0.52 \pm$ $0.06 \mathrm{~Hz} / \mathrm{pA}$ in control to $0.94 \pm 0.14 \mathrm{~Hz} / \mathrm{pA}$ after inhibiting Kv2 currents $(n=9$, significant at 0.01$)$.

Blocking BK channels had the opposite effect on the $f-I$ curve, decreasing the slope (Fig. $9 E, F$ ). In collected results, the slope of the $f-I$ curve decreased from $0.55 \pm 0.03 \mathrm{~Hz} / \mathrm{pA}$ in control to $0.33 \pm 0.02 \mathrm{~Hz} / \mathrm{pA}$ after blocking BK current $(n=11, p=0.004)$.

Although they affected spike shape and evoked firing, neither Kv2 or BK inhibition had a consistent statistically significant effect on pacemaking frequency in dissociated neurons. In most cases, as in the $f-I$ curves shown in Figure 9, $B$ and $E$, pacemaking frequency (ie, with no injected current) was affected very little, and the changes in the $f-I$ curve only became substantial for medium and large current injections. In a small number of cells, both GxTX-1E and paxilline exposure produced small increases or decreases in firing rate, but with no consistent direction. In experiments blocking BK channels by $300 \mathrm{~nm}$ paxilline, the spontaneous firing rate was $6.0 \pm 0.6 \mathrm{~Hz}$ in control and $6.1 \pm 0.5 \mathrm{~Hz}$ in paxilline $(n=14, p=0.70)$. In experiments with Kv2 inhibition, the spontaneous firing rate was $5.7 \pm 0.5 \mathrm{~Hz}$ in control and $5.4 \pm 0.3 \mathrm{~Hz}$ in $100 \mathrm{~nm} \mathrm{GxTx}(n=15, p=0.54)$.

\section{Complementary recruitment of $\mathrm{BK}$ and $\mathrm{Kv} 2$ channels}

A possible explanation for the paradoxical increase in the afterhyperpolarization resulting from BK channel inhibition is suggested by the different kinetics of $\mathrm{BK}$ and $\mathrm{Kv} 2$ channels. In the absence of BK channels, increased Kv2 current might flow to repolarize the action potential, partially replacing the lost BK current. If so, the much slower deactivation kinetics of the Kv2 current compared with BK current would give a longer-lasting conductance in the late phase of spike repolarization even though total potassium current earlier in the spike is reduced as a result of loss of BK current.

To test the idea that block of BK channels results in more activation of Kv2 channels, we compared the activation of Kv2 channels by action potential waveforms recorded either in control or after blocking BK channels (Fig. 10). We found that substantially more Kv2 current flowed during the waveform recorded in paxilline than during the control waveform. To quantify the change, we integrated the Kv2-mediated current flowing during each action potential waveform. The charge from Kv2 channels increased from $0.8 \pm 0.1 \mathrm{pC}$ in the control action potential waveform to $1.3 \pm 0.2 \mathrm{pC}$ flowing during the waveform recorded in paxilline $(n=18, p=0.0003)$, Thus, the broadening 
A

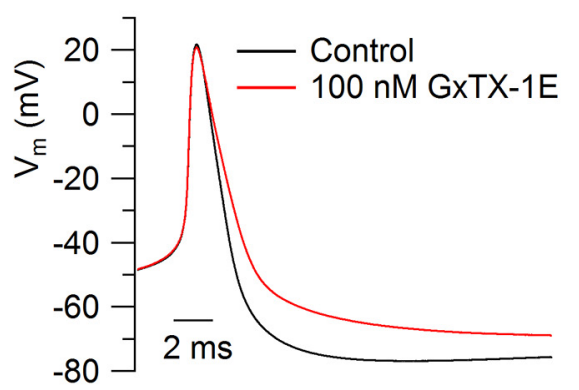

B
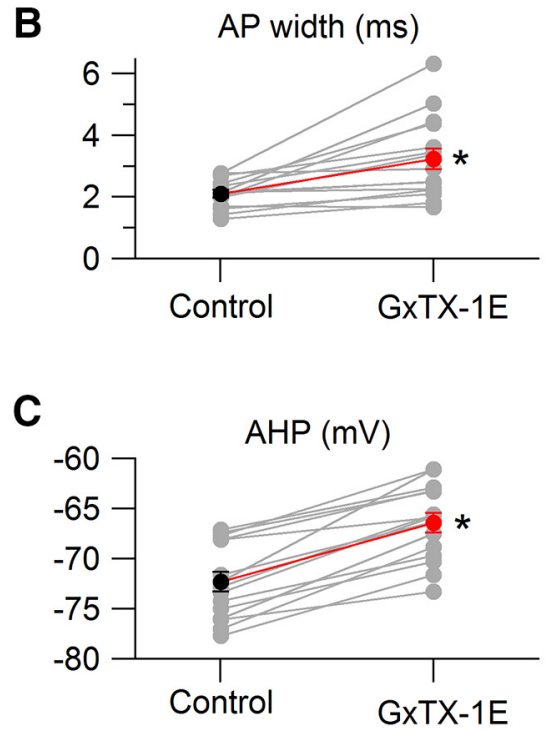

D
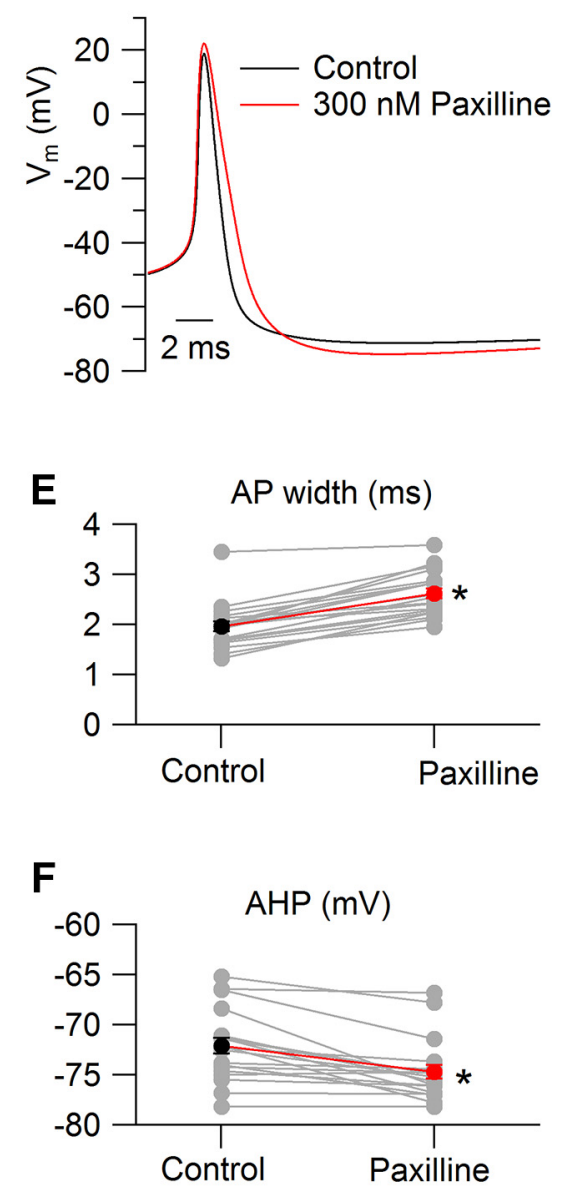

Figure 8. Different effects of Kv2 and BK inhibition on spike shape in dissociated SNc dopamine neurons. $\boldsymbol{A}$, Action potentials

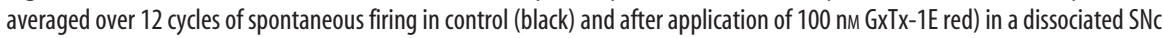
neuron. $\boldsymbol{B}$, Collected results for effects of GXTX-1E on spike width (measured at the threshold voltage) in 15 neurons. Gray symbols are individual cells; black and red points are mean \pm SEM for control (black) and after GXTX-1E (red). C, Collected results for effects of GXTX-1E on the afterhyperpolarization in the same 15 neurons. $\boldsymbol{D}$, Action potentials averaged over 12 cycles of spontaneous firing in control (black) and after application of $300 \mathrm{~nm}$ paxilline (red) in a dissociated SNc neuron. $\boldsymbol{E}$, Collected results for effects of paxilline on spike width (measured at the threshold voltage) in 19 neurons. $\boldsymbol{F}$, Collected results for effects of paxilline on the afterhyperpolarization in the same 15 neurons. $37^{\circ} \mathrm{C} .{ }^{*} p<=0.0008$.

of the action potential resulting from BK channel block results in enhanced activation of Kv2 channels.

In complementary experiments, we used the waveforms of spontaneous pacemaking recorded in control and after inhibition of Kv2 channels and measured the BK-mediated current flowing during each of these waveforms (Fig. 11). The integrated current mediated by BK channels increased from $0.9 \pm 0.1 \mathrm{pC}$ in the control waveform to $1.8 \pm 0.4 \mathrm{pC}$ in the waveform with $\mathrm{Kv} 2$ channels inhibited $(n=19, p=0.001)$. Thus, the altered action potential shape following Kv2 channel inhibition results in enhancement of BK current. However, the increased BK current evoked by the broader spike still deactivates relatively quickly.

\section{Discussion}

Despite extensive electrophysiological study of midbrain dopamine neurons, little is known about which potassium channels mediate spike repolarization. We found that both BK and Kv2 channels help repolarize spikes in SNc dopamine neurons, but with different kinetic properties that result in divergent effects for regulating firing.
Opposite control of evoked firing by BK or Kv2 inhibition

Our results show that when either BK or Kv2 channels are inhibited, the other type is activated more during the spike. This effect, along with their different kinetic properties, especially the slow deactivation of Kv2 channels, can account for the very different effects of Kv2 and BK inhibition on evoked firing. Kv2 inhibition produced faster firing and steeper frequency-current curves, while inhibition of BK produced frequency-current curves with unchanged or shallower slopes. When the curves were shallower, BK inhibition could slow evoked firing (Figs. 5B, 9D). The differential regulation of evoked firing can be understood by considering the different activation and deactivation kinetics of BK and Kv2 channels. The key elements are: (1) the slower, later activation of Kv2 current during spikes compared with BK channels; and (2) the slower deactivation of Kv2 current following spikes.

The speeding of firing after Kv2 inhibition is straightforward, from loss of a relatively long-lasting hyperpolarizing influence after the spike. Although enhancement of BK current partially replaces lost Kv2 current, this replaces a slowly decaying conductance by a faster-decaying conductance. Additionally, with Kv2 inhibition, the afterhyperpolarization shifted positive by $\sim 5 \mathrm{mV}$, shortening the subsequent depolarization to spike threshold and speeding firing. The effect of replacing Kv2 conductance by BK conductance would be greater at more depolarized interspike intervals (ie, for large current injections), because Kv2 deactivation kinetics become much slower, and less complete, at more depolarized voltages (Liu and Bean, 2014), whereas BK deactivation kinetics remain very fast and compete up to at least $-48 \mathrm{mV}$ (Fig. $1 A)$. This explains the greater changes for larger current injections and the steeper $f-I$ curves produced by Kv2 inhibition.

The slowing of firing sometimes caused by BK inhibition is counterintuitive, considered as simple loss of a potassium conductance. It can be understood by the compensatory activation of additional Kv2 current and the slower deactivation kinetics of Kv2 channels. This resulted in a modest $(\sim 2.5 \mathrm{mV})$ hyperpolarizing shift of the afterhyperpolarization after BK inhibition. This shift alone would tend to slow firing, but a bigger factor is likely the slower deactivation of the Kv2 conductance than the BK conductance it replaces, resulting in a longer-lasting potassium conductance that opposes subsequent depolarization after the spike.

\section{Effects on pacemaking}

One of the only differences between experiments in brain slice and dissociated neurons is that in slice both BK and Kv2 inhibition produced a modest speeding of pacemaking (from $2.9 \pm 0.2$ $\mathrm{Hz}$ to $4.4 \pm 0.4 \mathrm{~Hz}$ with iberiotoxin and from $2.7 \pm 0.2 \mathrm{~Hz}$ to 
$3.8 \pm 0.4 \mathrm{~Hz}$ with GxTX-1E), whereas there was no consistent effect on pacemaking in dissociated cells $(\sim 5-6 \mathrm{~Hz}$ in all conditions). The reasons for this difference are not obvious. Possibly the effects in slice involve channels in dendrites or the axon that are lost in dissociation. The difference could also reflect the difference in baseline firing frequency. During the slow pacemaking of dopaminergic neurons in brain slice, the net inward ionic current driving depolarization is only 1-2 pA for much of the interspike interval (Khaliq and Bean, 2008), so that very small currents from any conductance can modify pacemaking frequency. Both SK currents and Kv4-mediated $I_{\mathrm{A}}$ strongly regulate pacemaking frequency (Ping and Shepard, 1996; Liss et al., 2001; Wolfart et al., 2001; Hahn et al., 2003; Waroux et al., 2005; Deignan et al., 2012) and likely flow throughout the interspike interval. Interspike currents from $I_{\mathrm{A}}$ are larger when interspike voltage changes more rapidly (Khaliq and Bean, 2008), so that faster pacemaking likely involves both larger sodium and calcium generator currents and larger partially opposing currents from $I_{\mathrm{A}}$; under these conditions, the added effect of small currents from BK or Kv2 channels at the hyperpolarized interspike intervals typical of pacemaking may be minimized.

\section{Kv2 channel opposition of depolarization block}

A propensity to enter depolarization block is a hallmark of midbrain dopamine neurons (Grace and Bunney, 1986; Hyland et al., 2002; Blythe et al., 2009). Recent work has explored how sodium channel inactivation kinetics regulate entry into depolarization block (Tucker et al., 2012; Qian et al., 2014). Our results show that Kv2 current is another critical element for depolarization block. After inhibition of Kv2 currents, cells entered depolarization block with smaller depolarizations, an effect not seen with inhibition of BK channels. The promotion of depolarization block by Kv2 inhibition apparently occurs because the afterhyperpolarization produced by BK channels alone is insufficiently negative and long lasting to allow effective recovery from sodium channel inactivation, especially over repeated firing cycles. Promotion of depolarization block following Kv2 channel inhibition has previously been seen in cortical pyramidal cells, CA1 pyramidal cells, and superior cervical ganglion neurons (Guan et al., 2013; Liu and Bean, 2014).

\section{BK channel enhancement of firing frequency}

$\mathrm{BK}$ channels regulate firing in many types of mammalian neurons. In some, including cerebellar Purkinje neurons (Edgerton and Reinhart, 2003; Swensen and Bean, 2003; Womack at el., 2009), most vestibular nucleus neurons (Smith et al., 2002; Nelson et al., 2003), and cerebellar Golgi cells (Hull et al., 2013) inhibiting BK channels produces speeding of firing accompanied by reduction in the afterhyperpolarization, the changes intuitively expected. However, in CA1 pyramidal neurons, inhibiting BK channels has the counter-intuitive effect of slowing firing $(\mathrm{Gu}$ et al., 2007; see also Smith et al., 2002), an effect subsequently seen in several other neuronal types, including GABAergic neurons in the vestibular nucleus (Gittis et al., 2010) and intracardiac autonomic neurons (Pérez et al., 2013).

Two possible explanations for the ability of BK current to enhance firing frequency, or for inhibition of BK current to slow firing, have been suggested. One is that by enhancing the afterhyperpolarization, BK channels enhance recovery from inactivation of sodium channels. The second, proposed from modeling of CA1 pyramidal neurons firing (Gu et al., 2007), is that by providing rapid repolarization, BK channels prevent activation of other potassium channels with slower deactiva- 

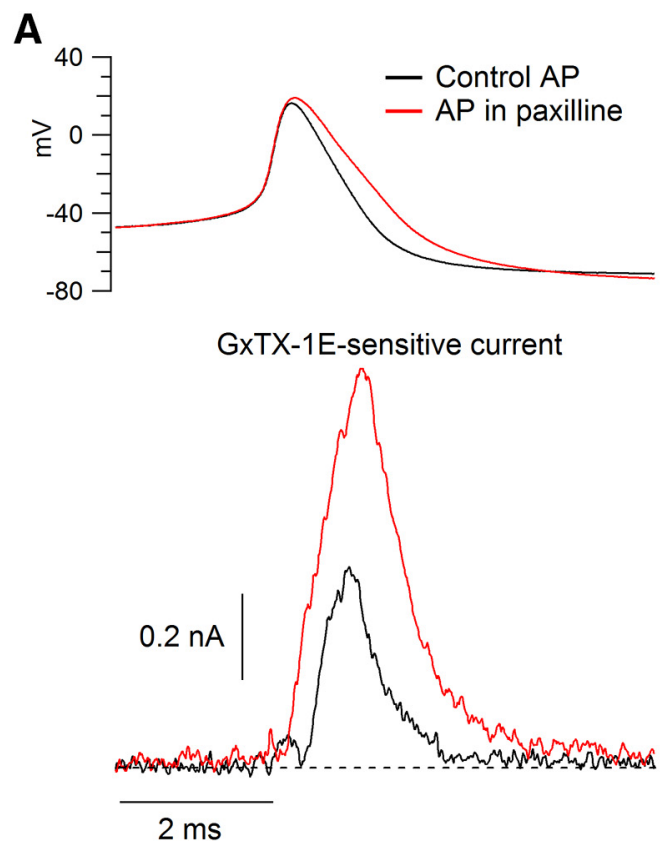

B

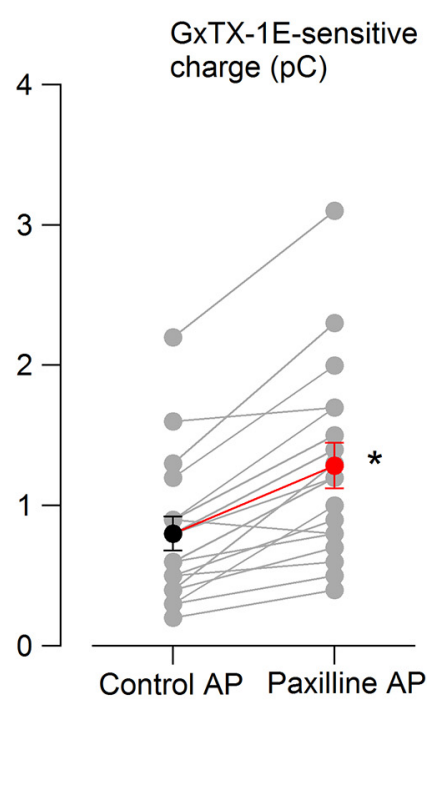

Figure 10. Recruitment of additional spike-evoked Kv2 current after BK inhibition. $\boldsymbol{A}$, Top, Action potentials recorded in control (black) and after application of paxilline (red). Bottom, Kv2 current evoked by the two waveforms. Kv2 current was obtained by subtraction using $100 \mathrm{~nm}$ GXTX-1E. B, Collected results in 18 neurons. Gray symbols indicate results in each cell. Black and red points are population mean \pm SEM for Kv2-mediated charge evoked by the control action potential (black) or the action potential recorded in paxilline (red). $37^{\circ} \mathrm{C} .{ }^{*} p=0.0003$.
A

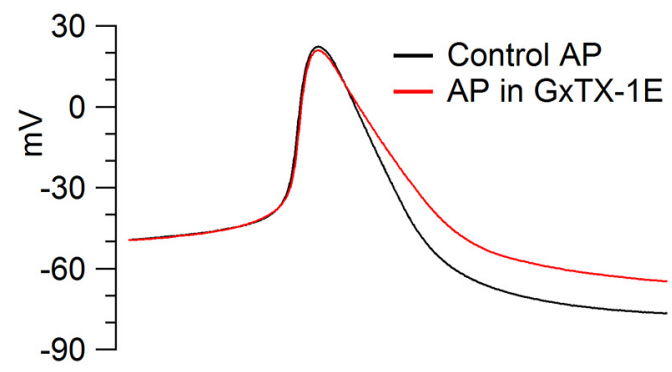

Paxilline-sensitive current

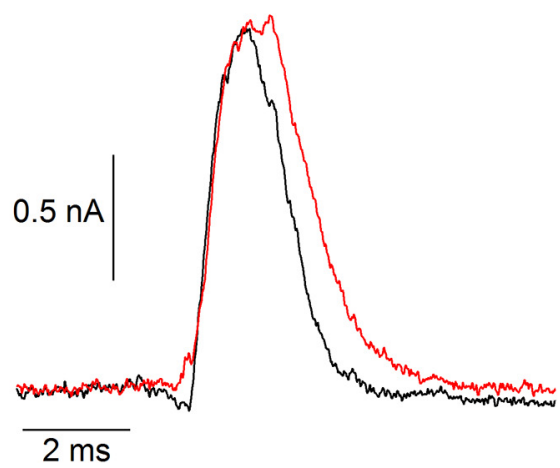

B

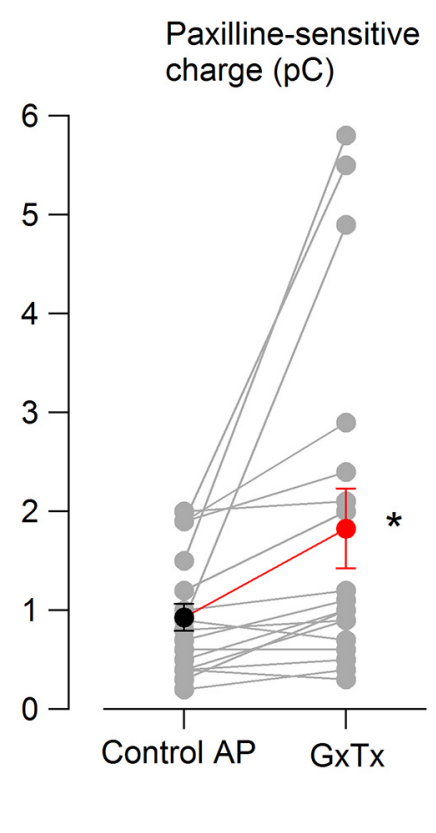

Figure 11. Recruitment of additional spike-evoked BK current after Kv2 inhibition. A, Top, Action potentials recorded in control (black) and after application of $100 \mathrm{~nm}$ GXTX-1E (red). Bottom, BK current evoked by the two waveforms. BK current was obtained by subtraction using $300 \mathrm{~nm}$ paxilline. $\boldsymbol{B}$, Collected results in 19 neurons. Gray symbols indicate results in each cell. Black and red symbols are population mean \pm SEM for control action potential and action potential recorded in GXTX-1E, respectively. $37^{\circ} \mathrm{C} .{ }^{*} p=0.001$.

The ability of BK channel activation to speed firing by short-circuiting activation of Kv2 or other slowly gating potassium currents may be fairly widespread. When fast-activating BK channels are enhanced by knock-out of the beta 4 subunit that slows activation, firing of dentate gyrus granule neurons becomes faster (Brenner et al., 2005). Similar effects have been seen with upregulation of BK current in suprachiasmatic nucleus neurons (Montgomery and Meredith, 2012) and cortical pyramidal neurons following picrotoxininduced seizures (Shruti et al., 2008). We speculate that short-circuiting of Kv2 activation may account for the effects of BK upregulation in these neurons, though this remains to be tested.

\section{Other channels}

Our results show that it can be difficult to interpret the functional effect of removing a given conductance, because activation of other conductances can change. Augmented spike-evoked Kv2 activation following BK inhibition is one example, but there could be others. For example, the broader action potentials produced by both Kv2 block and BK block would be expected to enhance calcium entry, which in turn would be expected to enhance SK current. Also, the changes in afterhyperpolarization seen with Kv2 and BK inhibition likely change the kinetics and extent of recovery from sodium channel inactivation. In addition, spike-evoked potassium current clearly involves contributions from channels in addition to BK and Kv2 channels (Fig. 8), whose activation or deactivation could also be affected by changes in spike shape. Further work will be needed to identify the full range of interactions among these many conductances that could potentially participate in regulating spike shape, pacemaking frequency, and evoked firing.

\section{Relation to in vivo bursting}

Although somatic current injection can evoke firing at burst frequencies (Blythe et al., 2009), natural burst firing evoked by synaptic input clearly involves a complex interaction between synaptic conductances and many voltage-dependent channels in both dendrites and soma. Previous experiments and computational modeling have identified a number of elements important for regulating bursting (for review, see Morikawa and Paladini, 2011; Paladini

tion kinetics. Our results provide direct experimental demonstration of the second hypothesis and identify Kv2 channels as a specific type of more slowly deactivating channel that can underlie the effect. and Roeper, 2014), including the voltage-dependent behavior of NMDA receptors (Deister et al., 2009; Lobb et al., 2011), intracellular calcium buffering (Grace and Bunney, 1984a), SK channels (Shepard and Bunney, 1991; Waroux et al., 2005), K-ATP 
channels (Schiemann et al., 2012), and the kinetics of voltagedependent sodium channels (Tucker et al., 2012; Qian et al., 2014). Our results now suggest that BK and Kv2 channels are also likely to be key elements for controlling spike repolarization during bursts, intraburst frequency, and depolarization block. The new information on their voltage dependence and kinetics can now be added to evolving computational models (Kuznetsova et al., 2010; Ha and Kuznetsov, 2013) to better understand how synaptic conductances, cable properties, and intrinsic membrane properties interact to control bursting.

\section{References}

Amendola J, Woodhouse A, Martin-Eauclaire MF, Goaillard JM (2012) $\mathrm{Ca} 2+/$ cAMP-sensitive covariation of $I_{\mathrm{A}}$ and $I_{\mathrm{H}}$ voltage dependences tunes rebound firing in dopaminergic neurons. J Neurosci 32:2166-2181. CrossRef Medline

Baranauskas G, Tkatch T, Surmeier DJ (1999) Delayed rectifier currents in rat globus pallidus neurons are attributable to Kv2.1 and Kv3.1/3.2 K(+) channels. J Neurosci 19:6394-6404. Medline

Blythe SN, Wokosin D, Atherton JF, Bevan MD (2009) Cellular mechanisms underlying burst firing in substantia nigra dopamine neurons. J Neurosci 29:15531-15541. CrossRef Medline

Brenner R, Chen QH, Vilaythong A, Toney GM, Noebels JL, Aldrich RW (2005) BK channel beta4 subunit reduces dentate gyrus excitability and protects against temporal lobe seizures. Nat Neurosci 8:1752-1759. CrossRef Medline

Chan CS, Guzman JN, Ilijic E, Mercer JN, Rick C, Tkatch T, Meredith GE, Surmeier DJ (2007) "Rejuvenation" protects neurons in mouse models of Parkinson's disease. Nature 447:1081-1086. CrossRef Medline

Deignan J, Luján R, Bond C, Riegel A, Watanabe M, Williams JT, Maylie J, Adelman JP (2012) SK2 and SK3 expression differentially affect firing frequency and precision in dopamine neurons. Neuroscience 217:67-76. CrossRef Medline

Deister CA, Teagarden MA, Wilson CJ, Paladini CA (2009) An intrinsic neuronal oscillator underlies dopaminergic neuron bursting. J Neurosci 29:15888-15897. CrossRef Medline

Ding S, Wei W, Zhou FM (2011) Molecular and functional differences in voltage-activated sodium currents between GABA projection neurons and dopamine neurons in the substantia nigra. J Neurophysiol 106:30193034. CrossRef Medline

Drion G, Bonjean M, Waroux O, Scuvée-Moreau J, Liégeois JF, Sejnowski TJ, Sepulchre R, Seutin V (2010) M-type channels selectively control bursting in rat dopaminergic neurons. Eur J Neurosci 31:827-835. CrossRef Medline

Dufour MA, Woodhouse A, Goaillard JM (2014) Somatodendritic ion channel expression in substantia nigra pars compacta dopaminergic neurons across postnatal development. J Neurosci Res 92:981-999. CrossRef Medline

Edgerton JR, Reinhart PH (2003) Distinct contributions of small and large conductance $\mathrm{Ca} 2+$-activated $\mathrm{K}+$ channels to rat purkinje neuron function. J Physiol 548:53-69. CrossRef Medline

Galvez A, Gimenez-Gallego G, Reuben JP, Roy-Contancin L, Feigenbaum P, Kaczorowski GJ, Garcia ML (1990) Purification and characterization of a unique, potent, peptidyl probe for the high conductance calciumactivated potassium channel from venom of the scorpion buthus tamulus. J Biol Chem 265:11083-11090. Medline

Gittis AH, Moghadam SH, du Lac S (2010) Mechanisms of sustained high firing rates in two classes of vestibular nucleus neurons: differential contributions of resurgent na, Kv3, and BK currents. J Neurophysiol 104: 1625-1634. CrossRef Medline

Goldman MS, Golowasch J, Marder E, Abbott LF (2001) Global structure, robustness, and modulation of neuronal models. J Neurosci 21:52295238. Medline

Grace AA, Bunney BS (1984a) The control of firing pattern in nigral dopamine neurons: single spike firing. J Neurosci 4:2866-2876. Medline

Grace AA, Bunney BS (1984b) The control of firing pattern in nigral dopamine neurons: burst firing. J Neurosci 4:2877-2890. Medline

Grace AA, Bunney BS (1986) Induction of depolarization block in midbrain dopamine neurons by repeated administration of haloperidol: analysis using in vivo intracellular recording. J Pharmacol Exp Ther 238:10921100. Medline
Grace AA, Bunney BS, Moore H, Todd CL (1997) Dopamine-cell depolarization block as a model for the therapeutic actions of antipsychotic drugs. Trends Neurosci 20:31-37. CrossRef Medline

Guan D, Tkatch T, Surmeier DJ, Armstrong WE, Foehring RC (2007) Kv2 subunits underlie slowly inactivating potassium current in rat neocortical pyramidal neurons. J Physiol 581:941-960. CrossRef Medline

Guan D, Armstrong WE, Foehring RC (2013) Kv2 channels regulate firing rate in pyramidal neurons from rat sensorimotor cortex. J Physiol 591: 4807-4825. CrossRef Medline

Gu N, Vervaeke K, Storm JF (2007) BK potassium channels facilitate highfrequency firing and cause early spike frequency adaptation in rat CA1 hippocampal pyramidal cells. J Physiol 580:859-882. CrossRef Medline

Guzman JN, Sánchez-Padilla J, Chan CS, Surmeier DJ (2009) Robust pacemaking in substantia nigra dopaminergic neurons. J Neurosci 29:1101111019. CrossRef Medline

Ha J, Kuznetsov A (2013) Interaction of NMDA receptor and pacemaking mechanisms in the midbrain dopaminergic neuron. PLoS One 8:e69984. CrossRef Medline

Hahn J, Tse TE, Levitan ES (2003) Long-term K + channel-mediated dampening of dopamine neuron excitability by the antipsychotic drug haloperidol. J Neurosci 23:10859-10866. Medline

Herrik KF, Christophersen P, Shepard PD (2010) Pharmacological modulation of the gating properties of small conductance $\mathrm{Ca} 2+$-activated $\mathrm{K}+$ channels alters the firing pattern of dopamine neurons in vivo. J Neurophysiol 104:1726-1735. CrossRef Medline

Herrington J (2007) Gating modifier peptides as probes of pancreatic $\beta$-cell physiology. Toxicon 49:231-238. CrossRef Medline

Herrington J, Zhou YP, Bugianesi RM, Dulski PM, Feng Y, Warren VA, Smith MM, Kohler MG, Garsky VM, Sanchez M, Wagner M, Raphaelli K, Banerjee P, Ahaghotu C, Wunderler D, Priest BT, Mehl JT, Garcia ML, McManus OB, Kaczorowski GJ, Slaughter RS (2006) Blockers of the delayed-rectifier potassium current in pancreatic $\beta$-cells enhance glucose-dependent insulin secretion. Diabetes 55:1034-1042. CrossRef Medline

Hille B (2001) Ion channels of excitable membranes, Ed 3. Sunderland, MA: Sinauer.

Hu H, Shao LR, Chavoshy S, Gu N, Trieb M, Behrens R, Laake P, Pongs O, Knaus HG, Ottersen OP, Storm JF (2001) Presynaptic Ca2+-activated $\mathrm{K}+$ channels in glutamatergic hippocampal terminals and their role in spike repolarization and regulation of transmitter release. J Neurosci 21: 9585-9597. Medline

Hull CA, Chu Y, Thanawala M, Regehr WG (2013) Hyperpolarization induces a long-term increase in the spontaneous firing rate of cerebellar Golgi cells. J Neurosci 33:5895-5902. CrossRef Medline

Hyland BI, Reynolds JN, Hay J, Perk CG, Miller R (2002) Firing modes of midbrain dopamine cells in the freely moving rat. Neuroscience 114:475492. CrossRef Medline

Jaffe DB, Wang B, Brenner R (2011) Shaping of action potentials by type I and type II large-conductance $\mathrm{Ca}(2)+$-activated $\mathrm{K}+$ channels. Neuroscience 192:205-218. CrossRef Medline

Johnston J, Forsythe ID, Kopp-Scheinpflug C (2010) Going native: voltagegated potassium channels controlling neuronal excitability. J Physiol 588: 3187-3200. CrossRef Medline

Khaliq ZM, Bean BP (2008) Dynamic, nonlinear feedback regulation of slow pacemaking by A-type potassium current in ventral tegmental area neurons. J Neurosci 28:10905-10917. CrossRef Medline

Knaus HG, McManus OB, Lee SH, Schmalhofer WA, Garcia-Calvo M, Helms LM, Sanchez M, Giangiacomo K, Reuben JP, Smith AB 3rd (1994) Tremorgenic indole alkaloids potently inhibit smooth muscle highconductance calcium-activated potassium channels. Biochemistry 33 : 5819-5828. CrossRef Medline

Kuznetsova AY, Huertas MA, Kuznetsov AS, Paladini CA, Canavier CC (2010) Regulation of firing frequency in a computational model of a midbrain dopaminergic neuron. J Comput Neurosci 28:389-403. CrossRef Medline

Liss B, Franz O, Sewing S, Bruns R, Neuhoff H, Roeper J (2001) Tuning pacemaker frequency of individual dopaminergic neurons by Kv4.3L and KChip3.1 transcription. EMBO J 20:5715-5724. CrossRef Medline

Liu PW, Bean BP (2014) Kv2 channel regulation of action potential repolarization and firing patterns in superior cervical ganglion neurons and hippocampal CA1 pyramidal neurons. J Neurosci 34:4991-5002. CrossRef Medline 
Llinás RR (1988) The intrinsic electrophysiological properties of mammalian neurons: insights into central nervous system function. Science 242: 1654-1664. CrossRef Medline

Lobb CJ, Wilson CJ, Paladini CA (2011) High-frequency, short-latency disinhibition bursting of midbrain dopaminergic neurons. J Neurophysiol 105:2501-2511. CrossRef Medline

Malin SA, Nerbonne JM (2002) Delayed rectifier K+ currents, I K, are encoded by Kv $2 \alpha$-subunits and regulate tonic firing in mammalian sympathetic neurons. J Neurosci 22:10094-10105. Medline

McCrossan ZA, Lewis A, Panaghie G, Jordan PN, Christini DJ, Lerner DJ, Abbott GW (2003) MinK-related peptide 2 modulates Kv2.1 and Kv3.1 potassium channels in mammalian brain. J Neurosci 23:8077-8091. Medline

Meera P, Wallner M, Toro L (2000) A neuronal beta subunit (KCNMB4) makes the large conductance, voltage- and $\mathrm{Ca} 2+$-activated $\mathrm{K}+$ channel resistant to charybdotoxin and iberiotoxin. Proc Natl Acad Sci U S A 97:5562-5567. CrossRef Medline

Misonou H, Mohapatra DP, Trimmer JS (2005) Kv2.1: a voltage-gated K+ channel critical to dynamic control of neuronal excitability. Neurotoxicology 26:743-752. CrossRef Medline

Montgomery JR, Meredith AL (2012) Genetic activation of BK currents in vivo generates bidirectional effects on neuronal excitability. Proc Natl Acad Sci U S A 109:18997-19002. CrossRef Medline

Morikawa H, Paladini CA (2011) Dynamic regulation of midbrain dopamine neuron activity: intrinsic, synaptic, and plasticity mechanisms. Neuroscience 198:95-111. CrossRef Medline

Neher E (1992) Correction for liquid junction potentials in patch clamp experiments. Meth Enzymol 207:123-131. CrossRef Medline

Nelson AB, Krispel CM, Sekirnjak C, du Lac S (2003) Long-lasting increases in intrinsic excitability triggered by inhibition. Neuron 40:609-620. CrossRef Medline

Paladini CA, Roeper J (2014) Generating bursts (and pauses) in the dopamine midbrain neurons. Neuroscience 282:109-121. CrossRef Medline

Pérez GJ, Desai M, Anderson S, Scornik FS (2013) Large-conductance calcium-activated potassium current modulates excitability in isolated canine intracardiac neurons. Am J Physiol Cell Physiol 304:C280-C286. CrossRef Medline

Petrik D, Wang B, Brenner R (2011) Modulation by the BK accessory beta4 subunit of phosphorylation-dependent changes in excitability of dentate gyrus granule neurons. Eur J Neurosci 34:695-704. CrossRef Medline

Ping HX, Shepard PD (1996) Apamin-sensitive Ca(2+)-activated K+ channels regulate pacemaker activity in nigral dopamine neurons. Neuroreport 7:809-814. CrossRef Medline

Puopolo M, Raviola E, Bean BP (2007) Roles of subthreshold calcium current and sodium current in spontaneous firing of mouse midbrain dopamine neurons. J Neurosci 27:645-656. CrossRef Medline

Putzier I, Kullmann PH, Horn JP, Levitan ES (2009) Cav1.3 channel voltage dependence, not $\mathrm{Ca} 2+$ selectivity, drives pacemaker activity and amplifies bursts in nigral dopamine neurons. J Neurosci 29:15414-15419. CrossRef Medline

Qian K, Yu N, Tucker KR, Levitan ES, Canavier CC (2014) Mathematical analysis of depolarization block mediated by slow inactivation of fast sodium channels in midbrain dopamine neurons. J Neurophysiol 112: 2779-2790. CrossRef Medline

Ramírez-Latorre JA (2012) Functional upregulation of Ca2+-activated K+ channels in the development of substantia nigra dopamine neurons. Plos One 7:e51610. CrossRef Medline

Sawamoto K, Nakao N, Kobayashi K, Matsushita N, Takahashi H, Kakishita K, Yamamoto A, Yoshizaki T, Terashima T, Murakami F, Itakura T, Okano H (2001) Visualization, direct isolation, and transplantation of midbrain dopaminergic neurons. Proc Natl Acad Sci U S A 98:64236428. CrossRef Medline

Schiemann J, Schlaudraff F, Klose V, Bingmer M, Seino S, Magill PJ, Zaghloul
KA, Schneider G, Liss B, Roeper J (2012) K-ATP channels in dopamine substantia nigra neurons control bursting and novelty-induced exploration. Nat Neurosci 15:1272-1280. CrossRef Medline

Shepard PD, Bunney BS (1991) Repetitive firing properties of putative dopamine-containing neurons in vitro: regulation by an apaminsensitive $\mathrm{Ca}(2+)$-activated $\mathrm{K}+$ conductance. Exp Brain Res 86:141-150. Medline

Shruti S, Clem RL, Barth AL (2008) A seizure-induced gain-of-function in BK channels is associated with elevated firing activity in neocortical pyramidal neurons. Neurobiol Dis 30:323-330. CrossRef Medline

Smith MR, Nelson AB, Du Lac S (2002) Regulation of firing response gain by calcium-dependent mechanisms in vestibular nucleus neurons. J Neurophysiol 87:2031-2042. Medline

Su W, Song X, Ji JJ (2010) Functional expression of a large-conductance $\mathrm{Ca} 2+$-activated $\mathrm{K}+$ channel in mouse substantia nigra pars compacta dopaminergic neurons. Neurosci Lett 471:1-5. CrossRef Medline

Swensen AM, Bean BP (2005) Robustness of burst firing in dissociated purkinje neurons with acute or long-term reductions in sodium conductance. J Neurosci 25:3509-3520. CrossRef Medline

Taddese A, Bean BP (2002) Subthreshold sodium current from rapidly inactivating sodium channels drivesspontaneous firing of tuberomammillary neurons. Neuron 33:587-600. CrossRef Medline

Tong H, Kopp-Scheinpflug C, Pilati N, Robinson SW, Sinclair JL, Steinert JR, Barnes-Davies M, Allfree R, Grubb BD, Young SM Jr, Forsythe ID (2013) Protection from noice-induced hearing loss by Kv2.2 potassium currents in the central medial olivocochlear system J Neurosci 33:9113-9121. CrossRef

Trimmer JS (1991) Immunological identification and characterization of a delayed rectifier $\mathrm{K}+$ channel polypeptide in rat brain. Proc Natl Acad Sci U S A 88:10764-10768. CrossRef Medline

Tucker KR, Huertas MA, Horn JP, Canavier CC, Levitan ES (2012) Pacemaker rate and depolarization block in nigral dopamine neurons: a somatic sodium channel balancing act. J Neurosci 32:14519-14531. CrossRef Medline

Vacher H, Alami M, Crest M, Possani LD, Bougis PE, Martin-Eauclaire MF (2002) Expanding the scorpion toxin alpha-KTX 15 family with AmmTX3 from Androctonus mauretanicus. Eur J Biochem 269:6037-6041. CrossRef Medline

Vacher H, Mohapatra DP, Trimmer JS (2008) Localization and targeting of voltage-dependent ion channels in mammalian central neurons. Physiol Rev 88:1407-1447. CrossRef Medline

Wang B, Jaffe DB, Brenner R (2014) Current understanding of iberiotoxinresistant BK channels in the nervous system. Front Physiol 5:382. CrossRef Medline

Waroux O, Massotte L, Alleva L, Graulich A, Thomas E, Liégeois JF, ScuvéeMoreau J, Seutin V (2005) SK channels control the firing pattern of midbrain dopaminergic neurons in vivo. Eur J Neurosci 22:3111-3121. CrossRef Medline

Wolfart J, Roeper J (2002) Selective coupling of T-type calcium channels to SK potassium channels prevents intrinsic bursting in dopaminergic midbrain neurons. J Neurosci 22:3404-3413. Medline

Wolfart J, Neuhoff H, Franz O, Roeper J (2001) Differential expression of the small-conductance, calcium-activated potassium channel SK3 is critical for pacemaker control in dopaminergic midbrain neurons. J Neurosci 21:3443-3456. Medline

Womack MD, Hoang C, Khodakhah K (2009) Large conductance calciumactivated potassium channels affect both spontaneous firing and intracellular calcium concentration in cerebellar Purkinje neurons. Neuroscience 162:989-1000. CrossRef Medline

Zhou Y, Lingle CJ (2014) Paxilline inhibits BK channels by an almost exclusively closed-channel block mechanism. J Gen Physiol 144:415-440. CrossRef Medline 